\title{
Replies to Commentators \\ on The Concept of Argument: \\ Clarifying Themes, Answering Questions, Settling Objections
}

\section{HARALD R. WOHLRAPP}

\author{
Universität Hamburg \\ Philosophisches Seminar \\ Von-Melle-Park 6 \\ 20146 Hamburg \\ Germany \\ wohlrapp@uni-hamburg.de
}

\begin{abstract}
The paper provides a series of responses to the papers published in Vol. 37, No. 3, of this journal that explored the ideas in Harald Wohlrapp's The Concept of Argument (2014), where arguing is understood as the theoretical or theory-forming activity that can be found in research of all kinds. Thus, the approach taken focuses on the validity of theses. This approach is clarified further as the author considers points raised by his commentators and provides answers and, where necessary, corrections.
\end{abstract}

Résumé: Cet article fournit une série de réponses aux articles publiés dans le vol. 37 , no. 3 dans lequel les auteurs explorent les idées contenues dans The Concept of Argument de Harald Wohlrapp (2014) où l'argumentation est comprise comme l'activité théorique ou l'activité qui forme une théorie qu'on peut trouver dans toutes sortes de recherches. Ainsi, l'approche adoptée met l'accent sur la validité des thèses. L'auteur clarifie davantage cette approche en répondant aux questions soulevée par ses commentateurs et en faisant les corrections qui sont nécessaires.

Keywords: justification, objections, objectivity, rhetorical argument, thetical validity, transsubjectivity

(C) Harald R.Wohlrapp. Informal Logic, Vol. 37, No. 4 (2017), pp. 247-321. 


\section{Introduction}

When I began to study argumentation, I was fascinated by the enigmatic relations between different paradigms as they appear, e.g., in the history of science and in the confrontation of cultures. Thomas Kuhn and Paul Feyerabend had declared them "incommensurable" and therefore called transitions between them "irrational". This caused a decades-long discussion in many disciplines, such as philosophy of science, sociology, psychology, history, and linguistics. My vague idea was that the problems did not so much point to a real lack of rationality as to our restricted and rigid conception of it. The basis of the restriction seemed to be the traditional concept of argument, which was minted by the patterns of formal logic, leaving no room for the subjective and historical aspects that are so important for said transitions. Thus, it seemed that a fundamental conceptual development was needed, requiring some wideranging philosophical considerations in turn.

At that time, I was luckily endowed with a fine research group at the university of Hamburg, and together we engaged in analyzing different kinds of argumentative endeavor. Of course, we became aware of the newly emerging wave of argumentation theory (in the wake of Toulmin, Perelman, Scriven, etc.). Yet, we had to learn, that scholars in that field were more concerned with providing an alternative to or replacement of logic than with basic conceptual renovations.

Therefore, we mainly followed our own intuitions, based on an intellectual background of ancient Greek thought, classical German philosophy and Dialogue Logic (which helped us steer clear of the troubles around the logical paradigm), and searched for a way to augment the concept of argument with dynamic and subjective structures. The result of 25 years of work was laid down in Der Begriff des Arguments ( $1^{\text {st }}$ ed. 2008). The book does not claim to exhibit a new approach or a new theory of argument; rather, it argues for an update of our general concep- 
tion that would make it suitable for covering our argumentative practice in a more comprehensive way.

The reception in Germany was very positive and resulted in the funding of the English translation: The Concept of Argument (hereafter TCA, see Wohlrapp 2014). In North America it was somewhat mixed. Some were sincerely interested (here I gladly and prominently name David Hitchcock), but the majority at first seemed to be rather alienated and skeptical.

The more I am grateful that, initiated by David Hitchcock and Derek Allen, the organizers of the OSSA 11 conference 2016, Hans Hansen and Christopher Tindale, arranged a panel on the book. After that, Blair and Tindale kindly published the reflected and enlarged contributions in a special edition of the journal Informal Logic - the issue preceeding this one: Vol. 37, No. 3 (September 2017).

My exquisite thanks, however, go to the five commentators, who have taken the trouble of making up their minds about a long and certainly challenging book. As a great many very different aspects appear in their contributions, I could only respond to the main themes and questions. Even this has grown to a paper of over 70 journal pages. I admit that this is a long sermon (containing five distinct parts) but I think I can promise to offer some unusual and possibly stimulating viewpoints for any argumentation scholar.

\section{Part I}

\section{Reply to Derek Allen: "Wohlrapp's concept of justification"}

Derek Allen's paper is a complex of considerations and arguments that have been a real challenge for me. They demand a determination of the relationship between my dialecticalpragmatist thinking and some of the prominent positions (Audi, 
Bonjour, Goldman) in the analytic section of philosophical epistemology. It is well known that this is a rugged and cleft territory, being full of problems and dead ends. Still, I am meanwhile very grateful for Allen's comments on my book-done in an air of diligence and sympathy for my work which I feel honored about - and thus giving me the opportunity to clarify my position in some relevant respects.

As I cannot answer all the details, I will concentrate on three topics. First, I will retrace Allen's confrontation of Goldman's and Wohlrapp's concepts of justification in more depth and discuss their reconcilability. Second, I will illustrate the differences with the help of Allen's physician example. Third, I will present some remarks about the "metaphysics" of the dialecticalpragmatist way of thinking.

\section{On Allen 1. Reconciling DP-justification (Wohlrapp) with IP-justification (Goldman)}

My commentator gives an account of my conception of justification (I will call it "dialectical-pragmatist justification", DPJ) and compares it extensively with traits of Goldman's "Interpersonal Justification" (IPJ). The leading question is whether and to what extent the two may be reconcilable. This is done with great care; still, there are some misunderstandings of my conception that I shall try to clarify.

I will provide a condensed account of my concept of justification (DPJ) that might serve to complete the picture traced by Allen. By contrast, I will then list the main characteristics of Goldman's IPJ, as far as I understand them. Subsequently, the reconcilability question will appear in a different light. Anyhow a positive answer is available.

\section{I - 1.1 Characteristics of DP-justification}

(1) DP-justification is the redemption of a validity claim that was advanced for a thesis. The content of the validity claim is 
Replies to commenators on The Concept or Argument 251

that the thesis be able to overcome an orientation gap. If the claim can be redeemed, the thesis is shown suitable as a new orientation.

(2) A DP-justification constructs a mental route (or web of routes) in single steps that build on each other, leading from certain grounds (bases, beginnings) to the thesis.

(3) The typical steps of a DP-justification are not formal but material (substantial), so that the whole route is not a compulsory but just a theoretically feasible guide to the thesis: DPJ is typically not deductive but epagogic: it invites someone to believe (trust) in the thesis.

(4) DP-Justification makes use of two types of theory: epistemic (old, proven) theory and thetic (new, assumed) theory. The safest kind of epistemic theory is knowledge. Knowledge, however, is not only justified by argument but by its incorporatation into human reality. (See Section 3.)

(5) There are two types of steps in a DP-justification: grounds (beginnings) and inferences (transitions). The grounds are safe because they ultimately rely on felicitous practices (common know-how). The rules or schemes of the inferences are safe insofar as they are themselves justified (which may be challenged and then has to be demonstrated).

(6) The success of any justification relies on the establishment of criteria of validity, which can be formal and/or material (substantial). A concrete application of a criterion, however, is not safe in abstracto, but requires the judgement that it fits within the concrete case.

(7) DPJ has an objective (epistemological) and a subjective (persuasive) side. The objective side concerns the theoretical attainability of the thesis. The subjective side concerns the insight that a reasoner may gain about how the orientation gap can be overcome.

(C) Harald R.Wohlrapp. Informal Logic, Vol. 37, No. 4 (2017), pp. 247-321. 
(8) DPJ is not monological, but dialogical: it is presented by a proponent in front of an opponent, who supervises the steps with regard to their feasibility. "Opponent" is a role which can only partially be taken over by real persons (having their subjective perspectives). Thus, the actual opponent is taken to be an agent of the open forum of arguments (i.e., a virtual dialogue, focused on the state of arguments achieved heretofore and continuously reopened whenever a new argument arises).

(9) The opponent's supervision can bring about objections against each part of a DPJ. The proponent then strives to settle the objections. Why?: His objective in this is not to win the dialogue but to gain a reliable new orientation.

(10) DPJ is successful if it can settle any objection presented by the opponent. Whether or not the opponent acquires an insight and/or accepts the thesis on the basis of the justification is up to $\mathrm{him} / \mathrm{her}$. Thus, the success of a justification concerns only the objective, not the subjective side (because, subjectively, we cannot sever illusion from insight).

\section{I - 1.2 Characteristics of IP-justification}

Alongside DPJ, I now list the traits of Goldman's concept as it is presented in the paper on "Argumentation and interpersonal justification" (Goldman 1995). ${ }^{1}$

(1) IP-justification originates from a doubt or contest that a belief, articulated in a proposition Y, can be justified, viz., that a person $\mathrm{P}$ may be justified in believing in $\mathrm{Y}$. This is only acknowledged if $\mathrm{Y}$ can be justified to be true, or, at least, truthconducive.

(2) IP-justification is addressed by a speaker $\mathrm{S}$ to a hearer $\mathrm{S}^{*}$; still, it is not dialogical. The hearer has no active function in

\footnotetext{
${ }^{1}$ I focus here on the general idea of IP-justification and leave aside the distinctions between "subjective/objective" and "creative"/"transmissional" IPjustifications.
}

(C) Harald R.Wohlrapp. Informal Logic, Vol. 37, No. 4 (2017), pp. 247-321. 
Replies to commenators on The Concept or Argument 253

how the justification is being shaped. His coming or not-coming to believe in $\mathrm{Y}$ is not the result of an assessment of the justification for Y but simply happens to him (if it happens to him)

(3) An IPJ justifies $\mathrm{S}^{*}$ to believe in $\mathrm{Y}$, if $\mathrm{Y}$ is the conclusion of an epistemically good argument.

(4) The goodness of the good argument - and, thus, of the IPJ -relies on the quality of its two elements: the premises and the connection of the premises to the conclusion.

(5) The connection of premises and conclusion in an IPJ is subject to the requirement of being deductive or inductively strong. (Whether or not this requirement is, in the actual case, fulfilled has to be judged by "us" (outstanding rational judges).)

(6) As to the premises, the hearer needs first to be justified in believing them. This is "a matter of evidence-possession by the person"-where "evidence-possession consists of a person's having certain beliefs and/or perceptual experiences". This is called personal justification. According to Goldman, "the core notion of justification is personal" (loc. cit., p. 58)-rather than interpersonal or social.

(7) Due to the personal character of justified belief in the premises, the epistemologically good argument is relative to a person. Thus, one person may be justified in believing the premises of an IPJ, while a second may not be.

(8) In order to be suitable for IPJ, the personal belief of $S^{*}$ in the premises of a "good argument" has to be confirmed from either "independent sources ... or from S's trustworthy assertion of them" (Goldman 1995, p. 58).

(9) An IPJ, if successful, transmits to the hearer a belief whose propositional articulation is true - at least it is "truth conducive".

(C) Harald R.Wohlrapp. Informal Logic, Vol. 37, No. 4 (2017), pp. 247-321. 


\section{I - 1.3 Comparing and reconciling DPJ and IPJ}

\section{(a) Backgrounds, reasons, motives}

In TCA justification is one of three "basic operations" that are part of a dialectical-pragmatist view of argumentation. The background is the view that, because argument is a central activity in human orientation building, its theory should be based on an anthropological foundation. DPJ applies to the necessity of convincing oneself of the reliability of a thesis that has been asserted in order to overcome an apparent gap in orientation.

Goldman's IPJ is a specific type of "epistemic justification". The quest for epistemic justification is also anchored in philosophy, but in a very special section. It results from the problem of defining knowledge with regard to the Gettier problem (Is knowledge really justified true belief? (Gettier 1963)). Goldman's IPJ has its specific goal in rooting epistemic justification in a social environment. At the same time, his concept is meant to resist Rorty's claims of a merely social, viz., political, nature of knowledge. Thus, the concept of "Interpersonal Justification" displays some social relationship but ultimately grounds in "Personal justification". Then, by way of a "good argument", a personally justified thesis should be transmissible to other persons.

\section{(b) Relationship between participants: Functions and expectations}

Participants in IPJ are speaker and hearer. The hearer is passive, may "come to believe" the respective conclusion. The speaker may dispose of a "personal justification" for some evidence or for some other beliefs whose propositional articulation can be taken as premises for an argument.

DPJ also has two distinct roles for participants: proponent and opponent. The opponent has an active function in building the justification: S/he supervises each step with regard to its feasibility and, in the wake of a doubt or contradiction, may ad- 
vance an objection. Thus, in DPJ the opponent can destroy the justification but can also enrich it - if an objection is produced which the opponent can integrate into the justification.

As to the reconcilability question, the roles of hearer and opponent are fairly different. Still, Allen has discovered a subtle possibility to reconcile the approaches in this regard: The inferences in an IPJ do not have to be deductive; they can also be "inductively strong". Now, Freeman is cited, who notes that "one way to test an inductive argument ... 'is to bring objections against it"' (Allen 2017, p. 174). This essentially creates the dialogue setting. Still, in light of Goldman's goal, this may not work very well. He surely wants the "good argument's" inferential elements to be safe due to standards that are external to the concrete speech situation of an IPJ. An inductively strong argument would require a high probability coefficient. Thus, reconcilability would only be possible if we allow the "standards" for the goodness of the argument to be open for revision in the concrete case. (But even then the objective of the whole businesstruth vs. valid new orientation-is reluctant to reconciliation.)

\section{(c) Structure of justification: Beginnings and inferences}

The character of the inferences in IPJ has already been discussed. In DPJ, an inference is a sequence of steps (or a web, containing several beginnings) that leads from available beginnings to the thesis. This sequence is not compulsory (not deductive and not even necessarily "strongly" inductive) but "epagogic". Each step only has to be feasible (without provoking contradiction or serious doubt); and the whole justification should build up the insight that the thesis indeed overcomes the underlying orientation gap.

Reconcilability is difficult with regard to the beginnings of the justifications. In DPJ, these are orientations which are already established (called "epistemic theories"). These include practical knowledge (know-how). In fact, this admission of the practical character of the origin of our orientations (and thus, of 


\section{Harald Wohlrapp}

knowledge) marks one of the fundamental differences between the two approaches. I will try to illuminate them - at least to a certain extent - in the last part of this answer.

IPJ begins with premises, i.e., propositions whose truth the speaker is "personally justified" to believe. The concept of personal justification is far from clear. Goldman thinks that if I perceive a cat in this room I am personally justified in believing that there is a cat in the room-whereas another person (who is not present) may be personally justified in believing this only on the basis of my trustworthy testimony. There is something in this that is correct. Yet, to state that this kind of justification is "personal" as opposed to "social", and even calling it "the core notion of justification", is erroneous. This view ignores the fact that we have socially learned not only how to use the word 'cat', but also how to perceive objects as cats. I am justified to believe in a cat's presence (when perceiving one) only if "we" would perceive a cat here.

The notion of personal justifications as being ultimately anchored in a single person's perceptual experiences may be a legacy of naïve empiricism ${ }^{2}$. An epistemic justification can justify a belief in Y as a "truth" only on the basis of a lot of wellestablished theoretical endowments, which are definitely not the possession of a single person, but rather common knowledge: For the sentence "A cat is present" is true", we have to know what a cat is, we have to know that the perceptional apparatus of the speaker is in appropriate condition, and we have to trust in the concrete application of that knowledge (which is generic in

\footnotetext{
${ }^{2}$ In order to illustrate its exclusive character, Goldman writes: “...the concept of P-justification would admit the possibility that young children before the onset of language should have justified perceptual beliefs (e.g. 'There is a toy under the table', expressed in the child's language of thought, not in public language which, by hypothesis the child has not yet learned)." (Goldman 1995, p. 56). This description ignores all the social activities by which the child has learned to orient him- or herself in the room, to identify items as "objects", etc.
}

(C) Harald R.Wohlrapp. Informal Logic, Vol. 37, No. 4 (2017), pp. 247-321. 
character and can have all kinds of exceptions in concrete cases). All of this can surely be in the possession of the speaker, but that person's capabilities are based not in the individual but in the social agent.

\section{(d) The goal of justification}

As IPJ is a species of epistemic justification, its goal is truth ${ }^{3}$. The truth concept is presupposed here. Discussions about that concept are directed to philosophy - and mostly to a realistic metaphysics which favors the "correspondence theory of truth". (See below in section I - 3.)

In DPJ, the goal of justifying a thesis is to show its suitability for orientation about the circumstances of an orientation gap. It should be clear that, if there is no orientation gap, then there is nothing to be overcome; and then DPJ does not apply at all. (In my answer to Ralph Johnson this question is tackled at some length.)

In general, the whole approach in which DPJ is embedded aims at a reasonable view of how human beings come to understand their circumstances and how they can improve their understanding. The difference between situations in which we are sufficiently oriented and situations in which orientation is missing marks the spot for presenting the claim of a thesis. It is true that this is a specific occasion for using arguments. Why do I take it as the starting point for theorizing argumentation? Because it is extremely important and it allows us to understand all the other relevant uses of argument based on this.

Argumentation is the intellectual side of investigative activities. Of course, those activities usually do not immediately lead to a true understanding of the issues. On the contrary, we may

\footnotetext{
3 “.... the idea of epistemic justification is parasitic on the notion of truth: to justify a belief is to provide some basis for thinking that it is likely to be true", Bonjour 1985, p. 163 (italics in text).
}

(C) Harald R.Wohlrapp. Informal Logic, Vol. 37, No. 4 (2017), pp. 247-321. 
follow a thesis that is more or less promising. The justification of such a thesis cannot be submitted to the requirement that it should be shown to be true. Why?: Usually, the understanding has to develop. Thus, truth can only be ascribed if the justified thesis proves to take hold in subsequent activities and considerations. Still, it must provide some orientation-hence its justification. It shall demonstrate that the thesis - which might look very promising - can be connected to our established theories without any serious mistake. Thus, the goal of DPJ is to show the suitability of the thesis as a new orientation based on which we can-provisionally_proceed.

Coming to an end with this section: What is the result of the whole comparison?

The general difference between DPJ and IPJ results from different tasks of argumentation. One sides assumes that we make believable or transparent some hitherto unbelieved or nonunderstood truth; the other side holds that we gain some guidance for new sections of reality which have not yet been fully penetrated by knowledge. A consequence of this difference is that epistemic justification, viz., justification concluding in knowledge, is restricted to cases of "pedagogical argumentation", viz., to the application of argument for the purpose of teaching. (I will come back to this further down.)

The reconcilability question finds an answer in the consideration that DPJ provides only the general form of a justification whereas IPJ describes a species which applies to certain special speech situations. (Are the qualities of an apple reconcilable with the qualities of fruit?)

\section{I - 2. Pragmatist vs. epistemic approach: A case study}

A central passage of Allen's paper provides a case study for discriminating the pragmatist from the epistemic concept of justification. Its motive is to illustrate and justify his doubts regard- 
ing my claim that "the epistemic approach in argumentation theory urges for a completion with a pragmatist foundation"4.

In order to confront the two approaches, he presents the following example: A patient $\mathrm{P}$, struggling with certain illness symptoms $\mathrm{S}_{1}, \mathrm{~S}_{2}$, sees a physician, who then, in a step-by-step sequence of argumentation and action, arrives at the diagnosis that $\mathrm{P}$ has illness $\mathrm{X}$, whereupon she decides to arrange a treatment $\mathrm{T}$ for the patient.

The example gives rise to a comparison of two narratives: one telling the story in a way that Allen qualifies as a "pragmatist treatment", and the other one telling the same story, but from the perspective of an "epistemic approach". 5

I have to confess that I found the differences between the two stories to be pretty small. The "pragmatist treatment" takes up some of my formulations ("no open objections", "suitable to function as a new orientation", etc.) which do not appear in the "epistemic treatment". Instead the latter contains more precise details than the former, and finally it enounces the physician's belief as "P has illness X".

(I would like to add here that this belief, being the result of an epistemic justification, should be appropriately worded as "it is true, that $\mathrm{P}$ has illness $\mathrm{X}$ "- - and in a prior version of Allen's text, that is indeed how it read: the formulation "it is true" was even italicized ${ }^{6}$. I suppose that this accentuation was skipped subsequently because Allen realized that he had ascribed the truth-goal to my concept of justification as well. This is, however, a misunderstanding. ${ }^{7}$ DPJ can lead to "true" orientations only

${ }^{4}$ See Wohlrapp's answers to commentators, Proceedings of the OSSA 11 conference, May 2016

${ }^{5}$ Readers are advised to recall the respective passages of Allen 2017, p 178f.

${ }^{6}$ E-mail correspondence with the author.

7 "A successful Wohlrappian justification will show that the validity claim raised by the thesis, namely that the thesis provides a reliable orientation, is true unless subsequent critical dialogue shows otherwise" (Allen 2017, p. 175 , italics in the text). I am sure that Allen is aware of the difference be-

(C) Harald R.Wohlrapp. Informal Logic, Vol. 37, No. 4 (2017), pp. 247-321. 
in the pedagogical variant of argumentation. (I will come back to this point in section $I-2.1$.)

I now turn to the question whether the epistemic treatment needs a pragmatist foundation or whether it "stands perfectly well on its own feet" (loc. cit., p. 179).

First, some corrections are needed in the example's "pragmatist treatment". In my view, a pragmatist story would read roughly like this:

There is a physician, who is admittedly competent in treating the diseases of patient P. She has a long acquaintance with $\mathrm{P}$, which constitutes a practice of trustful interaction between the two. This justifies the physician to take P's reports about symptoms $S_{1}$ and $S_{2}$ to be valid orientations. Moreover, as a person trained in the medical sciences, the physician has at her disposal her profession's bulk of theoretical knowledge and practical know-how. Based on this competence, the physician is justified in believing that the symptoms $S_{1}$ and $S_{2}$ are significant indicators for illness $\mathrm{X}$. In addition, she is justified in ordering tests to clarify whether or not $\mathrm{P}$ has $\mathrm{X}$. Part of the respective section of medical practice is the existence and reliability of labs that are able to perform those tests. Usually physicians work together with specific labs they have learned to trust, and so does this physician. She is therefore justified in believing that the positive test results, produced by "her" lab, are correct. On the basis of the test results she is subsequently justified to (logically) infer that "P has illness X". After this, she once more applies her professional orientation and determines that $\mathrm{T}$ is the adequate treatment for X. And, since there are no objections, she is justified in finally arranging $\mathrm{T}$ for $\mathrm{P}$.

tween the quality of the justified thesis and the quality of a sentence describing that quality. The latter, when using the knowledge about the Wohlrappian concept of thetic validity, can indeed be true, whereas the successfully justified thesis is only valid.

(C) Harald R.Wohlrapp. Informal Logic, Vol. 37, No. 4 (2017), pp. 247-321. 
Following this, I now turn to the "epistemic treatment" Allen has provided. It is noticeable that here the story is filled up with additional information about details, such as the probability coefficient of the connection between symptoms $S_{1}, S_{2}$, and illness $\mathrm{X}$, the directness of the physician's inspection of the X-rays, her high familiarity with medical literature, the proven reliability of the lab, etc. As a result, the physician is justified to believe that P has illness X; in Allen's words, "she is epistemically justified in believing this" (loc. cit., p. 179; italics in the text), (which means that she is justified in deeming it "true"). There seems to be a certain difference to the "pragmatist treatment", where things amount to quite the same result, but the conclusion comes without any stress on the "truth" of the diagnosis. Is this important?

I accept that all the additional details can make the nature of the physician's final belief more distinct and more elaborate. Yet, the striking fact is that this way of elaborating details will not really improve or increase the justification of her final belief.

This is only possible if we consider their being embedded in the underlying medical practices-which means switching over to the pragmatist view. Why? Without such considerations we find ourselves confronted with a sequence of single action steps and single steps of belief formation, whose justificatory power depends on the probability of each step. Still, despite each single step's high probability, it is clear that the summarized probability of the linked steps would be considerably lower. Thus, the "strong inductive support" of the single steps amounts to a support of the whole sequence that is less strong.

It is precisely here that the merits of a pragmatist view show up: It provides confirmation for the assumption that the probability values of the single steps, as well as that of the whole sequence, are high enough; after all, everything appears to be normal and in line with the state of the art in the respective section of the medical profession. I think this hint already suffices 
for an acceptance of the pragmatist view as a foundation of the epistemic view. However, I had claimed that the pragmatist foundation is not only a desirable addition, but that it is necessary for a completion of the epistemic view.

In order to understand this, let us assume the following continuation of the story: The treatment $\mathrm{T}$ did not work properly; $\mathrm{P}$ 's illness became worse quickly and then, still unexpectedly, $\mathrm{P}$ died.

Now, of course, a lot of questions and doubts will arise. The justification of the diagnosis and the treatment will be investigated meticulously in every detail. And now it becomes a striking fact that all the steps (except for the logical inferences) were not deductively valid but only had a high probability. As such, they will be open to doubts of this kind: Was her physical examination really careful enough? Was she possibly too familiar with the patient, so that she negligently took his reports about the symptoms $S_{1}, S_{2}$, to be sufficient for her diagnosis? Was there possibly a tiny gap in her account of the "relevant medical literature" which, albeit usually insignificant, proved fatal in this case? Were the x-ray slides the correct ones, etc., etc.

Confronted with such probing questions, the pragmatist view provides the only possibility to improve the epistemic justifications of the (inductively strong) inferences: It has to be shown meticulously that every step of the physician's belief building activities really and sufficiently conformed to the state of the art.

There are two more reasons for completing the epistemic view by way of a pragmatist foundation. In light of an epistemic justification, we might be inclined to feel safe. The conclusion that it is a truth (in the epistemic sense) that the patient has illness $\mathrm{X}$, sounds as if this was a final and definite diagnosis; and this, may endow the physician (and the patient) with a feeling of a perfect control of the situation. Based on such a feeling, one might be rather cut off from considering more and other possibilities. 
Replies to commenators on The Concept or Argument 263

I think this is not so enticing if the diagnosis is given in a pragmatist mood. Then it would be part of the physician's selfimage that her medical knowledge and know-how do not represent some absolute truths but that they are "generic" in character. They do not concern individual situations but types. Hence they allow for exceptions and other possibilities; and they are always open for refinement and improvement according to the concrete cases.

All this may still be regarded as no more than a tiny difference of attitude. Can it become important? This question leads to my second reason.

Let us assume, for the sake of the argument, that $\mathrm{P}$ indeed had illness $\mathrm{X}$, but also another illness $\mathrm{Y}$. Y is a rare disease, which is actually exacerbated by treatment $\mathrm{T}$. With regard to this extension of the example, I am inclined to believe that a pragmatic foundation of our beliefs and convictions simply allows us to be more open to considering other possibilities and keeping an eye on side phenomena.

The result of these considerations is the following: If Allen's case study is meant to demonstrate the characteristics of an epistemic view on justification as opposed to a pragmatist one, then, I would say, it actually exhibits a fundamental weakness of the epistemic view. The "epistemic treatment" of the story amounts to a result which apparently differs from the result of the "pragmatist treatment" only in its emphasis on the truth of the justified conclusion. But it is not difficult to put the case into a context in which the epistemic justification of the statement, that "it is true that P has illness X", is insufficient and needs a pragmatic foundation for it to be rounded up and improved.

\section{I - 2.1 Some remarks on Bonjour's concept of "epistemic justification"}

The last part of section 3. of Allen's commentary refers to Laurence Bonjour's concept of "epistemic justification". This is 
more general than Goldman's IPJ. Hence Allen's interest in also checking the reconcilability question against this view, which apparently is "endorsed by many analytic epistemologists" (loc. cit., p. 180). He then cites some of the programmatic passages from the beginning of Bonjour's work The Structure of Empirical Knowledge, where we are confronted with a demand to regard "truth" as "the goal of our distinctively cognitive endeavors: we want to correctly and accurately depict the world", and moreover, Bonjour writes, "the basic role of justification is that of a means to truth" (Bonjour 1985, p. 8).

It is obvious that these characteristics do not fit very well with what I have laid down about the argumentative operation of "justifying". I do not even believe that they fit very well with what a common speaker, let alone an argumentation theorist, would call "justification". Just take the following case: I am convinced that good education is a public task and that therefore the state shall provide the best educational institutions for its citizens. This thesis can be justified by explaining the connections between good education and serious political participation. It goes without saying that this issue deserves an enormous "cognitive endeavor". Some of the details will indeed be "facts" that have to be observed "correctly and accurately". But the main line of justification will make use of moral as well as legal norms and, in the end, of appeals to imagine a better society. All this is not a matter of "depicting the world" but of conceptually shaping a human reality in which we want to live. Justifications in discussions of that kind are neither able to function as "means" to truth, nor are they intended to do so.

Thus, what shall one understand from Bonjour's proposals concerning justification: Real justification exists only, or ideally, for the concerns of traditional natural science? But even in the case of statements like "Neonicotinoids are killing bees" (New Scientist 29. June 2017), there is no available justification which could claim to be "a means to truth" and "depict the 
Replies to commenators on The Concept or Argument 265

world"-because the causal relation which is admitted here is not a simple fact.

Despite this striking mismatch, Allen, in a well minded parallelism, picks up one small casual example from my book (This apple is not ripe yet (Wohlrapp 2014, pp. 136f.)) and demonstrates how it could be made compatible with Bonjour's demands. This is very carefully elaborated once more and, in principle, I could feel at ease with this additional proof of reconcilability. Still, one reservation must be stated. Allen mentions correctly that the example is a case of what I call "pedagogical argumentation".

This is the use of arguments in a dialogue with a clear "epistemic slope", usually the teaching situation. Its social structure involves one person who "knows" and (at least) one student who does not. The teacher might encourage objections by the student in order to give explanations which are apt to promote the student's understanding. Here justifications are indeed conducive to truth and they settle orientation gaps - but only on the part of the student. The student undergoes a process which shares some features with a research process, but whose result is already available. Clearly, this is a specific use of argumentation. For this use, the epistemic kind of justification seems appropriate.

\section{I - 3. Musings on the philosophical foundation}

In my last section, I will try to give at least a provisional answer to how we, in argumentation theory, can deal with the topics of knowledge and truth in a way that circumnavigates the metaphysical abyss.

The beginning of this line of thought is (again) the concept of "orientation". Orientation is a basic need-we share it with animals - and any animal that is able to survive is oriented well enough about the relevant conditions for survival. What is crucial now is this: Those conditions are not "presupposed" in the sense of an ontological postulate. They only appear in situations

(C) Harald R.Wohlrapp. Informal Logic, Vol. 37, No. 4 (2017), pp. 247-321. 
in which orientation proves to be defective, i.e., when the living and acting animal encounters an "orientation gap". And in those situations, the (newly emerging) conditions have no clear determination - they are no well defined "objects"-but they simply impede life and action in an accustomed and sufficiently oriented way.

If this can be understood, then it should be possible to say: The offspring of our idea of an "outside world" is nothing else but the "orientation gap". Prior to the emergence of the orientation gap, there is no such thing as a setting that involves the active subject in front of an objective world. Now, if we expand our line of thought from the animal state up to the conditio humana, then the "orientation gap" develops into the great impulse of questions, of research activities, of new understanding, of the growth of knowledge.

This has the following ("metaphysical") consequence: The determination of the objects that we are dealing with in our life is not prior to but is the result of our cognitive, emotional, and active endeavor to overcome all kinds of orientation gaps.

When this thought is grasped, we should be prepared to approach the concepts of knowledge and truth.

It is a lamentable fact that nearly all the work in contemporary epistemology (in particular after the Gettier-paper, half a century ago (Gettier 1963)) constructs the concept of knowledge with the help of the concept of truth. According to those doctrines, you can only "know" that there is a cat, if it is "true" that there is a cat. How can someone be sure about that truth? On this question there is a vast array of opinions. The most prominent answers demand some kind of correspondence between the content of the proposition and the circumstances of "the 
world $^{8 \%}$. This is a dead end for any controllable line of thought. It makes no sense to postulate a "cat" as an "objective" entity, independent of all our "subjective" forms of access, and subsequently muse about whether or not it "corresponds" to our concept of a cat.

Furthermore, in the context of considerations about the enigmatic nature of this correspondence, preference is given to sentences like "A cat is present", over sentences like "Man is born free". But why? Is freedom not "given" as an objective fact? ${ }^{9}$ Are ideals not part of the objective world? Is the "objective world" consisting of material particles alone — or of matter and material energy alone - and does not also contain, e.g., spiritual energy? Who can claim to "know" anything about this?

The course of thoughts which I have recommended in TCA (Wohlrapp 2014, Chap. 1.1-1.6.) displays a theoretical architecture that is new and uncommon (to the North American reader). It starts with a reflection on our know-how, whose correctness conditions are not theoretical but practical. Performing felicitous practice already includes some of the acting subject's basic orientations. The next step is the consideration of orientation gaps, then research activities (with argumentation as their cognitive layer), research results, a realization of the results in the way we shape reality, and a corroboration of the realized research results. The next great step is the establishment of "knowledge" as corroborated theory that shapes mankind and reality alike. After this, we can see that it is knowledge which allows us to justify a proposition as "true".

\footnotetext{
${ }^{8}$ Laurence Bonjour is also an adherent of corresponce theory. He hopes to mitigate the basic philosophical problems with Aristotle's truism "To say what is is, or what is not is not, is true", cf. Bonjour 1985, pp. 166f.

9 The idea of an outside world with objective structures is what Wilfried Sellars has criticised as "the myth of the given" (Sellars 1968, $\S \S 30,38$ ). Nowadays a lot of scholars (e.g., followers of Lewis) believe that they can ignore that critique.
}

(C) Harald R.Wohlrapp. Informal Logic, Vol. 37, No. 4 (2017), pp. 247-321. 
Thus, if we think in a pragmatist way and start with our practical capabilities and theorize their conditions and possibilities, and if we first conceive of knowledge and then of truth, we do not run into the metaphysical jungle with its ontological postulates. If, on the other hand, we start in the vein of epistemic approaches (viz., of Analytical Philosophy), we are sooner or later in need of a concept of truth. And, since that truth is concerned with the world in itself, it is supposed to be eternal or atemporal.

Once more, this is a heavy legacy of traditional philosophy. It can hardly cope with the fact that most of the certainties of mankind have been changed over the course of history. In a dialectical-pragmatist framework, knowledge and truth are not eternal or a-temporal, but rather "historical". Their contents can, in principle, always be improved-if further orientation gaps appear and call for further engagement in research. Thus, what to our ancestors was knowledge and what was truth need never appear as bluntly "false". It was restricted and has become less restricted. What we deem to be true knowledge today is nothing but a less restricted version of the truths of yesterday.

One last question: Why should this pragmatist thinking be more suitable for a theory of argument than the enigmatic grounds of epistemological approaches? My answer is this: Because it provides a philosophical foundation which can be justified within the realm of argumentation itself.

\section{Part II}

\section{Reply to Katharina Stevens (née von Radziewsky): "Does Rhetoric Have a Place in Wohlrapp's Theory of Argumentation?"}

Katharina Stevens's commentary is by far the longest, and it excels in a close and critical analysis of my treatment of subjec- 
Replies to commenators on The Concept or Argument 269

tivity, as it was elaborated, with the help of frame theory, in The Concept of Argument (TCA). Largely following my proposals, Stevens holds the view that a complete understanding of the frame mechanism requires attention to their communicative side. Consequently, she demands an extension of my concept of dialogue into rhetoric, notably by adapting some elements of Christopher Tindale's "rhetorical argumentation theory". In particular, she recommends the ideas of the "cognitive environment" and of a "universal audience". The whole paper is lucidly argued and admirably well illustrated.

I very much honor her sincere effort to connect the two approaches by Tindale and Wohlrapp, respectively, and I also appreciate her attempt at accomplishing a more complete theory of argumentation in that vein. The depiction of the problems around framing differences, in particular the "major problem", amounted to a real challenge for me. It made me rethink some parts of my views about subjectivity in argument and clarify the relationship between dialogue and rhetoric. Even if I am scarcely following her suggestions, I am grateful for her great endeavor of modifying and improving my views.

My answer will start with (1) a condensed survey of her line of thought and then focus on four items: (2) Insight, (3) Cognitive Environment, (4) the Leopold example, and (5) the Universal Audience.

\section{II - 1. The general thought line of Stevens's commentary}

The systematic beginning of Stevens's paper can be located in her assertion that the communication of insight is of "basic importance to all aspects of argumentation" (Stevens 2017, p. 184). In my theory, insight is considered the usual motive for adopting a certain thesis. It is not a criterion of its validity, because insight, even if it is clear and conspicuous, can be a subjective illusion. Hence the need for a dialogically supervised justification. Now, Stevens points to the fact that, in the course of a dialogue, communication is necessary for mobilizing adherence 
and establishing "shared insight" (loc. cit.). Thus, communication is a salient condition for the general possibility of arguing and, as such, merits special attention.

In my TCA, I did not treat the topic of communication and its problems because they are not specific to argumentation-even if they can become more acute in that domain.

Stevens regards the emergence of modern (viz., contemporary) rhetorical argumentation theory as the birth of a discipline that provides arguers with the tools for safeguarding their argumentative communication. One particular kind of communicative problem to which she directs her attention is this: the uses of frames and the fact that different persons can conceive the same issue in different frames, which may amount to different views about a thesis' meaning and validity. This fact can cause hindrances and blockages in communication. Particular importance is placed on the setting of "unacknowledged frame differences". They may cause what Stevens calls "the major problem [...] [which] brings the issue of argumentative communication into focus [...] because it constitutes its breakdown" (Stevens 2017, p. 191). The possibility of the problem is exemplified vividly and illustrated by way of fictitious dialogues, enacted by different observers of the famous "duck-rabbithead".

No doubt, the "major problem" is a real problem, including for my views on argumentation. If a thesis or argument comes in a frame that is alien to the opponent without this being acknowledged, then a possible absence of objections is no indication of validity. Therefore, a solution to this problem is needed.

Stevens recommends the adoption of Christopher Tindale's concept of the "Cognitive Environment" (CE). With the help of rhetorical tools, the opponent's $\mathrm{CE}$ shall be modified until communication is reestablished. Following this, the opponent should be able to advance objections whenever he or she disagrees with the thesis or justification. Stevens makes a considera- 
ble effort at explaining and illustrating said rhetorical tools, which are supposed to effect changes of the audience's CE. A striking example is an article in the early ecologist Aldo Leopold's "Sand county almanac". In it, a sophisticated pair of metaphors is summoned to trigger the reader's insight into a brand new frame. This new frame was: "the land as a moral patient". At that time (the 1940s) such a view must have been bluntly alien to the public. Thinking in that moral-patient-frame, landowners were supposed to be persuaded to stop their shortsighted exploitation of the forest and adopt a morally responsible relationship to their land. Stevens analyses Leopold's suggestion for reframing and estimates it to be a "a good example for the use of rhetoric to generate insight into new frames" ( $p$. 205).

Subsequently, she tackles the problem of possible misuses of rhetoric. She seems to believe that this problem can be handled by establishing a reconceived version of Perelman's, viz., Tindale's "Universal Audience" (UA). Thus she inserts two new features into the traditional conception of a fictitious community, formed by all reasonable human beings: At first, the addressee of a message shall not only be taken as an audience that is to be persuaded, but also as an opponent who is encouraged to advance objections. The second innovation is an ethical demand to respect the addressee's autonomy, i.e., not to exploit their ignorance or prejudices. Finally, Stevens recommends her new version of the UA as a "criterion for the acceptability of argumentative moves" (loc. cit., p. 209).

Any reader who is familiar with Perelman's original auditoire universel will realize that Stevens' proposal is quite a far cry from the inventor's idea. Yet, I am inclined to take it as an original and interesting attempt to find a criterion through which rhetoric could somehow expand its purely instrumental character. In what follows, I will closely consider Stevens' considerations and display my ongoing reservations around her efforts.

(C) Harald R.Wohlrapp. Informal Logic, Vol. 37, No. 4 (2017), pp. 247-321. 


\section{II - 2. The emphasis on "insight"}

Stevens correctly identifies that my skepticism about rhetoric is supported by the assumption that it can be used as an instrument for achieving the assent of an audience for whatever - good or bad-messages. This assumption is not beside the point if we consider the common use of rhetorical tools in politics and marketing. She believes, however, that modern (contemporary) rhetorical argumentation theory makes a difference, because it is concerned with providing theories and tools to achieve not only superficial assent but real insight.

In TCA, I have described insight as a kind of new understanding, i.e., a state of the mind in grasping a new thought. Certainly, in order to control the justification of some new thesis's reliability, an opponent has to gain insight into each step of the justification. And if Tindale's rhetorical argumentation is indeed a discipline addressing the efficient communication of insights, it follows that my theory of argumentative dialogue would be well advised to seek integration with rhetorical argumentation.

This is all obvious. Still, I am not convinced. For one, it is not immediately apparent that insight is something that could be communicated or "generated" (as Stevens puts it on p.185). Insight more or less befalls the mind. This is an occurrence that happens without a clear cause or a regular link to certain conditions. Thus, if I have a firm and clear insight into, e.g., the existence of miracles or of dark matter and I want to share it with you, then I can certainly communicate the meanings of the words that I am using. I can give you all kinds of descriptions and explanations of alleged facts. But I cannot literally make it that you get the respective insight.

A second doubt is this: We dispose of a variety of means to ensure communication, amply supported by all kinds of communication theories. Do we also need tools that are specifically designed for argumentation? I know of only one species of argumentation for which I would accept that. This is "pedagogical 
Replies to commenators on The Concept or Argument 273

argumentation"10. As I explained in Part I (answer to Allen), this is a special form in which the truth and value of the communicated matter can be presupposed. Therefore, it is in the student's own interest to gain an insight into the content and its justification. Here, the use of tools that foster communicationeven tools of whose functioning the student is not fully awareis legitimate.

In a discussion about a thesis aimed at overcoming an orientation gap, conditions are different. Here the proponent only claims that a certain view is valid. S/he may have a vivid insight into that validity. Yet, insight can be a stark illusion. Usually it is indeed insight that motivates people to adopt a new thesis or point of view. This is a reasonable move only if a justification has been provided which, in turn, has been scrutinized by a critical opponent. Sure, it is also necessary here that the opponent understands the arguments. Still, I can see no legitimation for forcing such insight based on any specific rhetorical tools.

To sum up: It is not clear why we should add to the extant theories about ensuring and improving communication a particular rhetorical discipline concerned with ways of fostering insight in argumentation.

\section{II - 3. Ruminations about the "Cognitive Environment"}

Stevens presents the notion of the cognitive environment (hereafter CE) as a true asset of Christopher Tindale's rhetorical argumentation theory. In consequence, she recommends its integration into the theoretical framework of TCA. After having studied it in Tindale's book (Tindale 2015, Chs. 7.8, 12.4) and having thought it over for a while, I ended up with the opinion that in argumentation theory we fare better without it. In the following, I will justify this result.

\footnotetext{
10 "Pedagogical argumentation" is treated in TCA, Chap. 4.

(C) Harald R.Wohlrapp. Informal Logic, Vol. 37, No. 4 (2017), pp. 247-321.
} 
In my theory, an arguer's subjectivity is theorized in the concept of an "orientation system" (OSY) (see Wohlrapp 2014, Ch. 3.3). This expression is used as a title for the whole semiotic tissue that is necessary for acting and thinking in the world as the person I am: it includes my knowledge, my beliefs, my habitual ways of perceiving, feeling, as well as the conscious forms my actions take. The OSY is a "system" in the sense that it is "closed", i.e., any new items are taken up in the specific forms that are characteristic for the subject. At the same time, this subject system has an environment to which it is "open": It can become aware of gaps in orientation (questions, problems, obscurities), which encourages it to look for "new orientations" (that can necessitate changes in the present OSY). So far, this is the form something like the $\mathrm{CE}$ takes in my theory: it is the horizon into which we look out for new orientation.

Up to now, I have not seen any need to develop a veritable concept of that environment. It scarcely appears in my book. Yet, Stevens' meticulous reading has found some traces of it under the title of a "dialogue context". Shall this context be conceived as something like the orientation system's environment? How could that environment be determined and limited - if it is not simply the whole world? One possible answer would be: It can only consist of those parts of the world which are, in principle, accessible and relevant for the subject's proper orientation.

Let us consider an example. For the ancient Greeks a mobile phone (viz., the technology to construct it) was not among the preconditions of their arguing. They did not know about it, and, even more importantly, they did not miss the respective knowledge because they did not know that they did not know ${ }^{11}$. Thus, nobody came up with the idea that Ulysses could be helped if somebody provided him with the latest I-phone model. Instead, according to the respective $\mathrm{CE}$ pertaining to Homer and his audience, what had to be invented to bring him home was

${ }^{11}$ This is the "exponential ignorance" which is treated in TCA, Chap. 5.

(C) Harald R.Wohlrapp. Informal Logic, Vol. 37, No. 4 (2017), pp. 247-321. 
another goddess or king's daughter. For us, however, a lot of facts, as well as wishes and phantasies around mobile phones have become part of our cognitive environment. This is due to the fact that they belong to our world. Thus, the development of new possibilities for acting and theorizing has created new sections of the CE that are relevant for us. But again: what is the use of this way of talking?

Tindale has tried to provide some clarification about the meaning of the CE. He traces it back to Sperber and Wilson, where it was introduced in analogy to the visible environment: "manifest facts and assumptions," Tindale writes, "are for conceptual cognition what visible phenomena are for visual cognition" (Tindale 2015, p. 144). Tindale then expands the notion further in order for it to embrace "not only facts and assumptions, that are manifest to us, but also a fund of collateral beliefs in light of which we interpret and understand that material, once it becomes noticed" (loc. cit., p. 146). He highlights three characterizations, which are (a) that a person's EC is "not simply cognitive ... but both, cognitive and emotional" (loc. cit., p. 122); (b) that it is "continuously modified as long as we live in society" (loc. cit., p. 122); and (c) that it "conditions the reception of argumentation" (loc. cit., p. 122).

I will briefly discuss these three qualifications with regard to the question what the use of the EC (in this sense) could be for the theorizing of argumentation.

\section{Ad (a)}

The quality "cognitive", as it is intended in Tindale's work, refers to his plea against a separation of cognition and emotion whose protagonists he identifies with Plato, Descartes, and Kant. Contemporary argumentation theory should be concerned with "the whole organism ... [in which] emotion, cognition, and the physical body are integrated" (loc. cit., p. 153). I gladly agree with Tindale in rejecting a strict separation between emotion and cognition. At the same time, I strictly dismiss his con- 
sequence, which seems to be a form of fusion that renders cognition emotional and emotion cognitive, as well. This amounts not only to a rejection of the separation but in fact dismisses any clear distinction between the two. Certainly, Tindale intended it to be a more natural and realistic view of the circumstances. In fact, what it really does is discard conceptual differences which are necessary for clear orientation.

We need this distinction, particularly for argumentation, because in an argument we can be affected cognitively as well as emotionally, and even bodily. The crucial question about that intricate affection, however, is which part or capability shall have priority. Rhetoric, as already Plato had seen clearly, cannot provide an answer; it seems to be neutral in this respect. Yet, because of the dangers of demagoguery we have to insist on prioritizing cognition above emotion and body reactions. Therefore, I regard a redefinition of the term "cognitive", which undermines that distinction not as a theoretical progress, but as a loss.

\section{Ad (b)}

The continuous modification of a person's CE in the sense of his/her changing capability to be affected by an argument is a trivial fact. What is not trivial, however, is whether or not the ongoing modification amounts to personal development, education, and progress, or instead to stagnation or even degeneration. I think that this depends on the person's choices in determining new orientations which try to bridge and overcome continuously emerging orientation gaps. Whether they can succeed in doing so, however, depends primarily on the quality of arguments that are considered and on the judgment capabilities acquired so far.

\section{Ad (c)}

As we human beings are generally limited, we are also limited in our ability to deal with arguments. With respect to these limits, it seems significant to focus on the "preconditions of arguing 
... (and/or of) the reception of argumentation" (loc. cit., p. 222). Those preconditions are, to a certain extent, specific to any given person, and they develop along with that person's own development. E.g., we can say that a young child lacks the CE for receiving the speeches in a national election campaign. This is why young children do not have the right to vote. But besides such rather crude estimations an ascription of sufficiency to a person's CE with regard to a particular argument is nothing but an arbitrary guess. In general, we have to take a back seat and content ourselves with the statement that, if an audience grasps an argument, then its CE was sufficient; but if not, we do not know why.

If the question of the sufficiency of a specific audience's CE for a specific argumentation is brought up seriously, then a lot of theoretical and empirical research work is necessary. Only on the basis of those findings could one try to engage in a gradual process which at first examines the audience's CE and then maybe enlarges it in a controlled way, so that finally the actual argument can be delivered with the prospect of being received.

As for pedagogical settings, this kind of investigation can be considered helpful. At the same time, it seems not to be of utmost importance, because here the members of the "audience" are still developing their personalities, which includes the development of their CE.

\section{II - 4. The Leopold example}

Now I will turn to Stevens's major example for the invention of a new frame through "powerful invitational rhetoric". She provides a rhetorical analysis of a paper by Aldo Leopold. In it, the author suggests to his American compatriots to see and treat the forested land "as a moral patient". I admit that I completely agree with Stevens's analysis, but I doubt that it shows an appropriate solution to the "major problem". For one, the message seems to have reached only a minority of the landowners. Even 70 years later, there are very few supporters of a morally justi- 
fied ecology. A non-believer does not necessarily have any objections against the 'moral patient'-frame for the land. It may simply not provide any insight for him or her. In my view, this shows that a solution to the problem may not be found in presenting a general way for reaching a new frame. Instead, what is required is an acknowledgment of the OSY of the individual interlocutor. This would mean, however, replacing the speakeraudience-scenery with a dialogue setting.

But even if this is done, there is still a general question: How can a proponent of a thesis, using a new frame, be justified in modifying the opponent's OSY? Stevens seems to expect that, out of the modified OSY, the opponent would be able to advance an objection which would not appear at all otherwise. I agree that this possibility could justify a modification of the opponent's OSY (or CE), but I am not sure that this is a realistic expectation. Very often the frames are closely interwoven with the thesis so that the claimed validity of the thesis presupposes the appropriateness of the used frames. This means that making the frame accessible to an opponent amounts to persuading $\mathrm{him} / \mathrm{her}$ of the thesis. If, however, the frame's appropriateness should be discussed beforehand, then the frames have to be manifest; which means that we are no longer dealing with the "major problem".

Let me add a warning concerning the evaluation of Leopold's argumentation as a "good rhetorical argument". It is easy to agree that it was (and is) able to convey a valuable insight. But as I already said (and as Stevens mentions, too, even though this does not always seem to be on her mind): insight is not a criterion for validity. A vivid and impactful experience of insight has the potential to seduce people into believing in the validity (value, correctness, and even truth) of a thesis that is presented to them. It is exactly this fact which constitutes the success of demagoguery. Rhetoricians and theorists of rhetoric prefer to praise the speeches of the "good guys" and tend to downplay the role of the great demagogues in history. 
Replies to commenators on The Concept or Argument 279

Still, a rhetorical argumentation theorist must never forget that, e.g., the infamous "Sport-Palast" speech by Hitler's propaganda minister Joseph Goebbels was a rhetorical masterpiece. Evidently, it employed strong metaphors, presence, repetition, evocation, etc. The conclusion was the proposition of ten fateful questions ("Do you want total war?") which were enthusiastically affirmed by an enthralled audience. Here is my question: Are we inclined to call that speech "good rhetorical argumentation"? Or would we not silently reserve that qualification for issues that are likely to be truly valuable?

\section{II - 5. Stevens's conception of the Universal Audience}

Allow me to begin with a flashback. Originally, the Universal Audience (hereafter: UA) was meant to make a distinction between two crucial attitudes or intentions a speaker may have in front of an audience. These were designated with the traditional terms "persuasion" and "conviction". Their difference was supposed to be determined by the way of addressing either the "particular audience" (i.e., the actual listeners) or the "universal audience" (i.e., the totality of reasonable human beings represented by the listeners - at least potentially). Perelman's followers had to struggle with at least two obvious questions: How is the UA conceived by the actual speaker, and how can "we" know that someone is indeed addressing the UA?

This was my motive for including a critique of the UA in my TCA. The main point was that the UA had been conceived as a traditional audience of passive listeners who were either persuaded or not. Any other reaction - other than acceptance or non-acceptance - was not possible. In particular, such an audience was not expected to advance their possible objections or corrections to the speaker's argumentation.

Stevens takes up this critique in the present proposal. Her new UA is constituted by "the ethical demand to respect every audience in its status as an opponent" and to treat them appropriately. This is a significant change, but not a complete trans- 
formation. The typical setting of rhetoric, where the audience has to be persuaded, is still assumed. Persuasion, however, shall not only lead to an audience's assent, but to real insight. In particular, this includes that the audience is moved to think in new frames. Finally, the performance of such persuasion intended to convey an insight may not exploit any weaknesses in the audience or the interlocutor. This means (a) that the speaker may not play on obvious ignorance or prejudices; and (b) that he/she may introduce new ways of framing "not covertly so that the manipulated person does not realize what is happening ... (but) out in the open" (Stevens 2017, p. 207).

I hope that the main features of Stevens' idea are clear: the UA becomes manifest in argumentative practice if the audience is assigned a real opponent position and is treated in a way shaped by the true acknowledgement of their autonomy ${ }^{12}$.

Is this a plausible enhancement of Perelman's UA? Is it a rhetorical version of my model of dialogues which critically investigate thetical validity?

I have great difficulty to fancy a positive answer to one or the other question. If I imagine a real situation of the kind that is characterized here I can no longer perceive a rhetorical speakeraudience-setting. Rather, it is a discussion group in which one participant gives a presentation and each other participant (maybe even the speaker) is granted the role of opponent. This kind

${ }^{12}$ Stevens proposal could gain more relevance when connected with Tindale's newly conceived UA. This UA "stands in the background of the audience that is addressed, but is brought to the fore in interaction with that audience ... (It) involves no necessary sameness of agreement ... (and makes even) ... apparently contradictory positions correct ... seeing the reasonableness at work in each context" (Tindale 2015, p. 218). He even ascribes a persuasive power to that UA, so that it is not us who may change our minds, but "our mind changes us" (loc. cit.. p. 223). This is a great idea, almost an echo of Hegel's "absolute spirit". The question is: how to access this UA? In my view, an answer would be: arguers committed to a transsubjective attitude may develop faith in the power of reason.

(C) Harald R.Wohlrapp. Informal Logic, Vol. 37, No. 4 (2017), pp. 247-321. 
of setting exists in think tanks, business teams, and, most prominently, in philosophical seminars. Of course, such a group has to continuously clarify the meaning and value of the disputed issues; i.e., it has to carefully provide an insight to any participant who asks for it. Yet, I doubt that the nature of their efforts is what we would usually call 'persuasion'. In addition, I also doubt that rhetoric plays a prominent role in such cases.

Whenever a misunderstanding of the kind of the "major problem" arises in such a group, it will either go unnoticed, in which cases some opponents do not fully understand the issue but are barely aware of it, and others do understand and utter their comments; or it will be treated by suggesting a look at the issue from this or that new point of view-i.e., from a perspective other than the familiar frame in which the addressee has, until now, looked at it. Thus, if Stevens's version of the UA would be enacted like this, then, once again, the "major problem" would not cause a real obstacle. Every new frame that appears to be alien will be made manifest. It will be carefully explained and, if necessary, justified in its appropriateness. New frames that do not provoke critical questions will simply go unnoticed (by the present arguers - while on the "forum" 13 they might eventually appear).

In other words: if this new UA employs a meaning of 'persuasion' that grants the addressee the power to consider and decide whether or not s/he will accept a new thesis or a new frame, then this kind of "persuasion" is no longer distinct from "conviction". Furthermore, the respect which is demanded for the audience of a rhetorical argumentation is nothing but a species of the general respect which we always owe to the autonomy of the other. In this regard, it is not easy to figure out a specific rhetorical sense of this "criterion for the acceptability of argumentative moves" (Stevens 2017, p. 209).

\footnotetext{
${ }^{13}$ This refers to "the open forum of arguments"which completes the determination of validity. An explanation with reference to Ralph Johnson's comment is given in Part IV of this paper.
}

(C) Harald R.Wohlrapp. Informal Logic, Vol. 37, No. 4 (2017), pp. 247-321. 
Despite all of these reservations I agree, of course, that the demand to acknowledge the other's autonomy is of immense importance for any reasonable conception of argumentation. Therefore, I have presented it as one aspect of the great principle of reason in argument, the "Principle of transsubjectivity"14.

A final statement:

My answer to the title question of Stevens's commentary would be this: Wohlrapp's theory of frame structures may indeed be useful for rhetoric. On the whole, the approach offers a background for restricting rhetoric to its reasonable function as a discipline that can foster not only mere assent but also reflected conviction about presented assertions. This does not mean, however, that it could contribute to the determination of their validity. 15

\section{Part III}

\section{Reply to Trudy Govier; "Issues of Logicism and Objectivity"}

For several decades I have tried to enter a discussion with Trudy Govier concerning her views about theorizing argument, and, in particular, about an appropriate analysis of Wellmann's "Conductive Argument". Since about the late 1980s I had hoped to draw her attention to several criticisms that had resulted from our research work in Hamburg. However, except for one short meeting in the lobby of an ISSA-conference, we have not had a real exchange. She had probably gotten the impression that the

\footnotetext{
${ }^{14}$ See (Hitchcock 2017) and my answer down here in Part V.

${ }^{15}$ Tindale's talk of "felt reasons" (Tindale 2015, pp. 186f) should be explicitly limited to contexts where the reasonableness of the reasons is granted (e.g., education); otherwise we need a conceptual distinction to the (intensively felt) "reasons" of Hitler's star rhetorician J. Goebbels.
}

(C) Harald R.Wohlrapp. Informal Logic, Vol. 37, No. 4 (2017), pp. 247-321. 
gap between our respective views was simply too large for us to form a substantial and fruitful mutual understanding.

I was all the more glad when she took the trouble to participate in the panel discussion on the $11^{\text {th }}$ OSSA about The Concept of Argument (TCA); and I am even more grateful the she has not written an extended commenting contribution to the Special issue of Informal Logic. I will do my best to understand and answer her arguments. There are two parts in her paper, both concerned with some rather fundamental structures of the theory of argument.

\section{III - 1. Logicism, the PPC structure}

Govier has clearly understood that my dissatisfaction with "Logicism" as a characteristic of the Informal Logic approach-and so of her own-does not mean I insinuated that Informal Logic has an inclination towards identifying arguments with patterns of (deductive) logic. What I criticize under the title "logicism" is rather the basic thought pattern in which an "argument" is a sequence of premises (including inference schemes) and a conclusion-my acronym for this was "the PPC-Structure". In my view this thought pattern is an ironic legacy of Informal Logic's insurgency against formal logic. In her commentary, Govier rejects this opinion claiming that "the identification of premises and conclusion is a preformal task" (Govier 2017, p. 211). What does that mean? She explains that even for a formalization one needs to know which statements have to be formalized. But this answer is insufficient because neither of us is very interested in a logical formalization of arguments. So why urge the indispensability of the PPC- pattern? Do we need it in order to become aware of an argumentative structure at all? In a former version of the present commentary she had said that the PPC-pattern "pre-dates formal logic". This would be a clear statement if it meant that one can encounter an identification of premises and conclusions even in the argumentative endeavors before Aristotle. Yet, regrettably, this is not so. In Plato's dialogues we do not 
find anybody asking for premises in order to support a conclusion-whereas the quest to justify one's theses (logon didonai) is omnipresent. On the other hand there appears in Aristotle's Topoi the word protaseis. This word signifies sentences that an arguer must select in order to derive from them the very thesis that he has chosen to defend (Aristotle 1960, Topica I, 14: 105a34). Thus, this expression can be adequately translated as 'premises'. Here, the speech situation is defined as a strictly regulated competitive dialogue. And because the Topoi are older than the Analytica (where the syllogisms are invented) what we find there can be regarded as an early version of the formalization of argument.

For this reason I think we should accept that the emergence of argumentative patterns with a clear PPC-structureconsisting of propositional and inferential sentences-coincides with the discovery of formal deductive structures. I can imagine that Govier might try to save her case by claiming that in any argument we have a kind of inference or transition. Through this inference some presupposed assumptions are taken to generate support for some other claims that were doubtful before. To this I agree, but then the meaning of "premises" rather blends into the meaning of "justification". I'm not sure that this really fits into Govier's line of thought. (This question is dealt with below.)

At any rate, my commentator is possibly in error with regard to my general estimation of the PPC structure. I am not plainly dismissing it. The salient point of my criticism is the role which it plays in the Informal Logic approach — namely to serve as the fundamental idea or pattern of what an "argument" is at all. This is profoundly misleading. To be sure, a PPC sequence can be the product of an argumentative endeavor. But on the one hand this is not necessarily so; and on the other, its information value is unclear because this kind of "product" is abstracted and severed from the process in which it was generated. 
In Hegel's dialectic there is a general reservation about such a procedure (Hegel 1977, Phenomenology of the Spirit, Preface), and as far as I can see, this is justified. Things are not simply what they appear to be. Very often the potential changes and movements they might undergo, and therefore an adequate determination of what they are and what they represent, depend on a clear understanding of their coming to be. For Aristotle a (true) slave was a human being with a slave-nature (and insofar as people had that nature their being slaves was justified) (Aristotle, 1972, Politics 1254a18). In the course of history mankind has, however, learned, that a "slave nature" is the product of treating a human being as inferior.

The standardization of the essence of arguments as a PPC sequence was brought about in the history of thought. We all know that the emergence of logic as an academic discipline has played a major role in that standardization. One of the side effects of this was the view that the justification of a thesis in an argument consists in presenting some premises from which the thesis can be derived (with the help of an identifiable inference scheme). Today's adherents of the "product approach" believe that it is natural to "understand" an argumentation by identifying such a structure in the utterances as they appear. I have found it difficult to come to an agreement with those scholars about the fact that such a product does not speak for itself. On the contrary all kinds of questions (about definitions of words, meanings of utterances and evaluations of matters of fact) have to be answered in order to determine the meaning of the sentences showing up in the respective PPC token. Sure, the adherents of the product approach recognize that there is a problem of interpretation. But they see this as an additional and independent question; and not one whose answers can be worked out only through a close observation of the process.

I would like to take the opportunity to state somewhat explicitly that Govier is caught in a perspective which is rather common, but too narrow, when she describes the "product ap- 
proach" and the "process approach" as opponents. It follows logically from this perspective that someone who speaks against the product approach must be an adherent of the "process approach". However, this is a mistake. The two approaches are not necessarily opponents. On the contrary, they belong together and an adequate theory of argument has to represent their interdependence. And as for my own thinking: For more than twenty years I have argued, in some of my papers, that the two are falsely isolated and that a recombination is necessary. In TCA I give a rather extensive explanation of how that can be done.

Further, I wish to remind the reader that the way in which Informal Logic models argumentation in the "product approach" has led to a complete ignorance of the role and function of "objections" in argument. In the end, Ralph Johnson had to take on the great effort of requesting a "dialectical tier" for a more comprehensive theory of argument (Johnson 2000, pp. 165-168).

The most striking effect of the thought pattern which is due to the product approach is, in my view, Govier's systematization of Wellmann's invention of a "conductive argument". (This will be tackled in section 2 of my answer.)

I will now turn to explaining why the concept of a "premise" (or a premise group) should be distinguished from the concept of an "argumentative justification". The subject was already tackled in my answer to Derek Allen. But as this distinction seems widely unacknowledged in Informal Logic it might be helpful to provide another, sharply pointed summary.

The relation thesis-justification is a pragmatic relation whereas the relation premises-conclusion is a syntactic - at best a semantic one. Premises are sentences from which the conclusion can be derived somehow. This is determined by investigating whether the premises are acceptable (at best: true) and whether the inference to the conclusion is valid (at best: formally valid). A justification, on the other hand, can be a complex aggregate of definitions, sentences, and sometimes samples of 
established practices and of transitions which are not necessarily of the if-then form. Furthermore, it can include abstractive or reflective steps for which presently no standardized patterns are established. In general, the concept of a justification (in my sense) is not defined by its syntactic form but by its pragmatic function: It should guide the dialogue partner to a reliable insight into the content of the thesis - namely in its suitability to overcome an orientation gap and to serve as a new orientation.

As for examples I will sketch another one, that might be more cogent for my present opponent: For the use of words and sentences in a certain language there exists a justification: it enables us to understand each other and to provide orientation in the world. If, however, a sentence like "There is a cat" fails to be simply agreed upon (e.g., with a small child or a stranger) it can always be justified with a hint to the use of the word 'cat'. This justification may be shaped artificially with sentences that can look like "premises": Cats are animals, they utter sounds like "meow", etc. But, in principle, offering "criteria" for the correct application of the word 'cat' does not help a bit, because for them to work, we have to rely on the same foundation: language use. Therefore, in this case language use as a practice is the beginning of the justification. Yet, it is not a "premise". Language use has to be learned - if one is not familiar with it. Once one is familiar with it, an attempt to justify the cat-sentence can appeal to the established practice from which the statement about the cat simply follows. It does not, however, "follow" via a recognizable inference scheme. The use of words in ordinary language is not (completely) determined by externally describable rules.

I am not sure if Govier would agree to consider this appeal to an established practice as (part of) "an argument". If not, then her reason would very likely be that an argument has to consist of premises and conclusion. In my view an argument is some- 
thing which is meant to convey an insight into the suitability of a thesis as a reliable bridge to overcome an orientation deficit. ${ }^{16}$

Can these views be reconciled? The only possibility that I can figure out is to reflect on what it is that we are doing when we condense and reduce a justification to a group of defined premises: we separate the product (i.e., a possible product) from the process. This is a move which can be done only with certain reservations. I have tried to explain the difficulties above by referring to Aristotle's slave concept.

The specific shortcoming that I have recognized in the systematization of conductive arguments is exactly this: a list of pro and con arguments is a product of a process. When we produce a conclusion from the pros and cons ( for example by outweighing or counting them, perceiving their relative importance) then this can only be an argumentative procedure, if the process that has led to those pros and cons, is continued. That would mean that each side is discussed further, and this would possibly include adjusting their frames etc. Any other procedure determining a conclusion might appear plausible or even cogent, but is not argumentative. It relies either on additional external tools (e.g. formal decision theory) or, and this seems to be the usual case, it is a blunt decision.

\section{III - 2. Metaphor and Objectivity in Weighing Arguments}

In the second part of my answer I will deal with Govier's attempt to investigate and criticize my objection against the CAmodel. In her commentary she concentrates on my claim that words like "weighing" or "outweighing" - that are supposed to designate the central operation in her $\mathrm{CA}$ - are no real concepts but just metaphors, signaling an objectivity that is not there.

Her defense against this objection takes the following form: First she refuses to recognize my qualification that "weighing"

${ }^{16}$ See the definition in Wohlrapp (2014), p. 270.

(C) Harald R.Wohlrapp. Informal Logic, Vol. 37, No. 4 (2017), pp. 247-321. 
is no more a (dubious) metaphor than a significant argument. She does this through a discussion of the use of metaphors. In a second step, she uses a tu-quoque argument to turn the metaphor reproach against my own use of the word "frame" for the description of subjectivity in argument. I think that neither step is a very well-reasoned attempt to clarify the discussion. I will explain why.

She begins with the following idea: If "weighing" in the context of argumentation is a metaphor, then we have to clarify whether that metaphor is alive or dead. Why? The expression could only suggest the alleged objectivist associations (of measurable quantities) if it is a live metaphor. And only then could my reproach bear some plausibility. If, however, it is a dead metaphor, then no one can be blamed for falsely suggesting an objectivist content. Therefore, she concludes, I had to presuppose the aliveness of the metaphor in my criticism. As a consequence, I have the burden to prove that this is so. Below I will investigate and try to settle this argument.

In the background of the whole consideration there seems to stand Govier's conviction that the "weight" of an argument is a merely subjective quality. She had exposed this view in her contribution to the panel discussion and she had illustrated it with a realistic example. ${ }^{17}$ In my answer I had taken up that example and had firmly argued against her view. ${ }^{18}$ Now, in this secondthoughts-paper, she makes no attempt to explicitly defend her view. Instead, this time the topic appears only at the margin. "Weight" is renamed as "Importance" and it is seen as being simply relative to arguers - with a few exceptions where issues may be (objectively) more important than others. I confess that I had certain difficulties to determine what she really means here. (I will give it another try towards the end of this answer.)

${ }^{17}$ See Govier's comments on the OSSA 11 book Panel on The Concept of Argument, in: OSSA Archives 2016.

${ }^{18}$ See Wohlrapp's Answers to commentators on the OSSA 11 book Panel on The Concept of Argument, in: OSSA Archives 2016.

(C) Harald R.Wohlrapp. Informal Logic, Vol. 37, No. 4 (2017), pp. 247-321. 
Govier does mention my proposal to integrate the subjective and the objective elements in the conclusions of Pro- and Conarguments with the help of frames (deploying the subjective perspectives), frame processing (criticizing, ranking, harmonizing, or synthesizing them) and "retroflexive" moves. However, I see no sign of agreement or disagreement. Instead, she states that any issue in arguing is given its particular importance through considerations made from merely subjective perspectives. Even if she concedes that "some considerations are more important than others" (Govier 2017, p. 220; italics in text), she seems to believe that this cannot been shown by examining the respective state of arguments about them and determining whether or not they can be settled against all available objections (which is my criterion for valid theses).

I would now like to answer the arguments Govier presents in defense against my criticisms:

I firmly believe that it does not matter whether "weighing" is a dead or a living metaphor. (Moreover, I think that if this question seriously arises, it should not be answered through the opinion of a philosopher but instead through the investigation of an empirical linguist.)

At any rate, such an answer is not necessary for my criticizing the vague meaning of a "weight" of arguments. What I have exposed in TCA is rather the following: Weighing and counting have their clear meanings with regard to scales and numbers. For arguments we simply do not have such parameters. Therefore, someone who talks about "outweighing" the Pros against the Cons in an argumentation, does not exactly know what s/he is actually doing - at least does not communicate it. If the metaphor is still working, then 'outweighing' means at least: "something like outweighing"- but without an indication what it precisely means. And if the metaphor is dead then the word signals only that some adjusting procedure has taken place. 
Is it possible that Govier simply misunderstands the nature of my criticism and the quality of my alternative proposals? Maybe I should explain once more and as precisely as I can what my point was. In using metaphors like "weighing" and "counting" arguments (be they dead or alive) we are using words of ordinary language - we are not making use of theoretically developed concepts. As long as we want to speak about arguments in colloquial talk we may certainly do so. (I would not mind people saying things like "I don't like your argument, it is so weak, you should present a stronger one" etc.) As soon as we start to theorize about the structure of Pro and Con argumentation, however, we have to go beyond this state of affairs. We have to enter an area of reflection where we search for relevant distinctions, we try to recognize crucial circumstances, relationships, connections, demarcations, and we have to articulate what we found in words and sentences. Their meaning will no longer be open but instead it will be under the control of the theorists. A word that shall designate such a crucial operation as the transition from certain pro and con arguments to a conclusion can, of course, not be a simple colloquially used metaphor. This is what I consider the deeper flaw in Govier's account of the CA: The consciousness of having left ordinary language behind and having entered a theoretically reflected sphere seems to be lacking. So far my criticism.

I have already indicated that it is not impossible that the whole quarrel about the metaphor problem relies on a basic misunderstanding. This suspicion might be supported by Govier's second move against my metaphor criticism. Here she turns the same objection against my use of the word 'frame', which I had introduced for theorizing the subjective side of arguments. This word, she suggests, is similarly nothing more than a metaphorsignaling a spatial content. Therefore, its use is also pretending an objective matter of fact which is not there. I rather doubt that this is a good argument. Sure, 'frame' is also a word of colloquial language and it bears a metaphorical content of spatial associations. I did not, however, exploit even the slightest meta- 
phorical sense in using it for my theorizing about subjectivity. Instead, I provide an extensive theoretical introduction of the term "frame structures", illustrated with a series of shorter and longer examples over the whole 55 pages of the respective chapter of TCA (cf. Wohlrapp 2014, Ch. 5: Frame Structures). The essence of the concept of "frame" is that it designates the restrictions and limits which are characteristic for a subjective perspective. Those limits are present when certain aspects of a discussed issue are not taken for relevant, sometimes they are not even considered at all and very often this goes without any awareness of the "blind spots". All this can cause what Stevens has called the "major problem" (see Stevens's commentary and the previous answer). In other words: The way in which an issue is habitually "framed" in a person's view is extremely important for the extent to which that person understands, misunderstands or completely dismisses an argument about that issue.

Furthermore, the concept of frame (in this sense) is not only a tool for explaining certain shortcomings in argumentation, it also opens up the possibility for attempts at corrections. Under certain circumstances frame limits can be postponed, crossed, or even overcome. Then a route to a new understanding opens up. The treatment of this topic in my book gives at least an impression of that possibility (cf. Wohlrapp 2014, Ch. 5.7).

I hope that these few remarks will have a chance to clarify the difference between the use of the expression 'frame' in my approach and the use of the expression 'weight' in Govier's treatment of the CA.

My final concern in this answer to Trudy Govier is to deliberate about the differences between our views about objectivity in argumentation. Obviously, the topic of objectivity is a very large field. Therefore I cannot do more than point out the general direction where some clarification might be expected. We all know that objectivity plays a prominent role in argumentation theory when it comes to knowledge, truth and reality. In 
Replies to commenators on The Concept or Argument 293

TCA I have extensively dealt with these matters (cf. Wohlrapp 2014, Ch. 1); and in my answer to Derek Allen I have tried to deliver some specific statements. In Govier's present commentary the topic of objectivity is only treated as a possible counterpart to subjectivity and, in particular, as a task which is not attainable in the context of "conductive arguments". Therefore, I suppose, she thinks here within the scope of an alternative. To her, philosophers who are not satisfied with the vague and metaphorical (dead or alive) sense of a "weight" of arguments are requesting an "objectivity" for the conclusion. This, however, can only be achieved through an algorithm.

Govier strongly refuses that request and in this point I completely agree with her. Yet, I am afraid that agreement ceases when she now concludes that the Pro and Con arguments in a $\mathrm{CA}$ are characterized through an "apparently subjective nature of significance or importance. From one perspective a consideration maybe of great importance, from another, it may scarcely matter" (Govier 2017, p. 220). Thus subjectivity is an irremediable feature of those arguments. But then the question arises what on earth is useful about this kind of argumentative endeavor. Are we just confronting our respective samples of Pro and Con considerations and then everybody may decide according to his or her preferences?

In TCA I have shown that the situation is not quite as hopeless. We can attempt to find out about the frame differences and then look for possible ways of mitigating or overcoming them. There is no guarantee that this works out, but this does not devaluate an attempt.

This point is important, because, as I mentioned already, Govier has stated that "some considerations are more important than others" (loc. cit., p. 220; italics in text). I gladly agree to this, but how shall we find out, viz., justify whether or not a certain consideration is more important than another? Even if she seems to be aware that sometimes a non-subjective result of 
evaluating views and statements is adequate or even necessary, she apparently cannot conceive of a method to achieve it.

It may be appropriate to remember that I am here ruminating on the basis of what I have read in her papers and, in particular, what she has uttered in her present commentary. But so far, I cannot figure out how she thinks that sometimes a nonsubjective argumentative result could be achieved. I confess that I find this a bit embarrassing. Why not, at least, consider my proposal that this could be a state of argument around a thesis such that no open objections remain?

I am well aware of that such a state is primarily a theoretical scheme. The concrete application will have to deal with questions like what in the present case is an objection (is it a negation of the thesis, a modification, a desired or necessary amendment, is it even relevant? etc.) and what can be done to settle it. But still, I'm convinced this - the settling (i.e. refutation, integration, moderation) of the objections against the thesis and against the arguments - is the true aim of any arguer.

If someone believes that this is not even a theoretical idea without some obvious practical bearings, then the background of that belief may be something like this: Our world views are so manifold and heterogeneous that a state where no objections remain is a mere fiction. Indeed, the world seems somehow outof-control. Nonetheless, this concern ignores an incredible amount of mundane structures and circumstances that are indeed well justified. Even then we always have to deal with some idiosyncratics (or some blunt idiots) who are able to produce objections out of their their specific preoccupations. The Mafiafamilies in Southern Italy whose companies bury the garbage, poisoning the soil and the water and receive the payments for waste disposal, will, of course, object to any parliamentary motion that could be able to change that situation; automobile manufacturers will object to any efficient measurement for the control of built-in deterioration of parts; the US home office will go 
on objecting against any efficient attempt to close the Guantanamo prison; etc., etc.

All this is true, but we need not care about those objections. Any sound minded and well informed person can refute them. It is therefore true that some considerations are more important than others; and it is not true that this cannot be shown. I believe that it can even be made rather obvious - on the way which is paved in my approach to the concept of argument.

Allow me to conclude with a final remark about the alleged alternative between subjectivity and objectivity in argument. As soon as we have left the realm of knowledge and truth and have entered the open scenery of opinions, assumptions, theses and arguments, we can no more claim "objectivity" for our views. But despite this fact, it is not the case that our views are hopelessly subjective. If this was so then - to say it once againoffering arguments would be no more than explaining our worthy views to each other.

It is my conviction that a reasonable theory of argument should be and can be more ambitious. Overcoming subjectivity has to be seen as an everlasting pursuit of a realistic orientation in the world and of the organization of social life among human beings. Argumentation is its methodical vessel. The term "intersubjectivity" has been established to refer to any result that is meant to be binding for a larger audience. In TCA I have argued that the idea of "intersubjectivity" is a step forward, but it is not pervasive enough for a principle of argumentation. As a title for the attempt to seriously set back and overcome subjectivity I have borrowed (from the logician and philosopher Paul Lorenzen) the term "transsubjectivity". David Hitchcock has delivered an excellent account of it - to which I answer in the last part of this paper. Whoever wants to learn even more about it is 
kindly invited to study the last chapter of my book (Wohlrapp 2014, Ch. 10). ${ }^{19}$

\section{Part IV}

\section{Reply to Ralph Johnson: "Wohlrapp on the criterial side of validity: Some comments"}

In Ralph Johnson's commentary, I find a lot of congenial traits which I am delighted about. While being one of the founding fathers of Informal Logic, this scholar has nevertheless bravely engaged in overcoming its birth defects (restriction to structural thinking, primordial role of the PPC structure, everyday discourse as the model for argumentation, dismissal of all kinds of criticism and objection) and has continuously developed his views. By now he takes argumentation to be a process of ongoing intellectual improvement in which the consideration of criticisms and objections is of major importance (Johnson 2000, Ch. $6)$. This is a view that I gladly agree with.

The commentary circles around several aspects of the concept of (thetical) validity that I have developed in The Concept of Argument (TCA) and which I consider to be a substantive innovation in argumentation theory. The questions and criticisms of Johnson's paper are mainly attempts to confront my views on the decisive role of objections, viz. criticisms, with his own plea for a "dialectical tier" as a constituent of argumentation. Besides this important theme there are some concerns about the meanings of terms, viz. the appropriate use of words, one of which I take up in my first paragraph, because I realized that it has caused irritations also for other readers.

19 One aspect of it, namely its "quasi religious" character is critically discussed in David Hitchcock's commentary (Hitchcock 2017); see also my answer in Part V. of this paper.

(C) Harald R.Wohlrapp. Informal Logic, Vol. 37, No. 4 (2017), pp. 247-321. 


\section{IV - 1. Title of the book}

I had to become aware that the title 'The concept of argument' gives rise to misunderstandings in the North-American argumentation community. Even David Hitchcock, my most meticulous reviewer, has called it "misleading" (see Hitchcock 2015). Johnson in turn has found that my book presents "not just a new concept ... but an original theory of argumentation" (Johnson 2017 , p. 223; italics in the text). It was a surprise for me to stumble across this striking difference in the meaning of the word 'concept'. I had not intended to invent or propose "a new concept" (or a new definition for the word 'argument'). Rather, I meant to clarify and update the conceptual structures of what human beings may have in mind when they communicate their (affirmative or critical) reasoning. My understanding of this sort of endeavor is based on Wittgenstein's investigations, widely characterized as "conceptual". Yet, I will try to be more outspoken on this point: In my view a "concept" of $\mathrm{X}$ is nothing else than the title of a theory about X. As long as there is no theory behind our use of $\mathrm{X}$ in conversation, we simply deal with the word $X$. In everyday communication, we need no theorywhen using words like 'table', 'cat', 'pencil', etc., their meaning is just their use. But for the more demanding issues-e.g., "revolution", "culture", and also "argument"-we are (hopefully) dealing with concepts. They are built in a theorizing endeavor (as I already tried to explain in my answer to Trudy Govier), that leads to complex systems of rules, statements, definitions. Usually they need to be justified and very often they are disputed and (hopefully) improved continuously. Displaying such a system in detail, means to display a "concept". For a famous paradigm of the use of 'concept' which I had in mind I recall Gilbert Ryle's The Concept of Mind ${ }^{20}$.

\footnotetext{
${ }^{20}$ Surprisingly enough, Johnson himself seems not to be alien to my intentions when he writes in his great theoretical book (Johnson 2000, p. 102): "My main interest in this book lies with the concept of argument."

(C) Harald R.Wohlrapp. Informal Logic, Vol. 37, No. 4 (2017), pp. 247-321.
} 


\section{IV - 2. Meaning of the term 'objection'}

The criterion for the validity of theses (or "thetical validity") is an "absence of open objections". As this criterion is defined by way of the term 'objection', it is obvious, why this term is focused in my commentator's attention. Moreover, the crucial role of "objections" for argumentation is a topic on which Johnson's theory and mine are overlapping. Yet, as there are also differences in the theoretical design, a close investigation of the meaning was appropriate. In his studies on TCA, however, Johnson was led to the opinion that 'the term 'objection' is never defined". Thus, he deems it "problematic ... (that) no definition of this pivotal concept is provided" (Johnson 2017, MS pp. $5,6)$.

I will make an effort to settle this problem, at least in its obvious appearance. For a deeper solution, my present endeavor might not be sufficient as that problem ultimately is located in the different theoretical backgrounds.

At first it might be informative that my theorizing was directed at an understanding of the practice of arguing. Since this practice consists of activities, I primarily cared for a depiction not of theoretical objects or units, but of action-types. Arguing is constituted by three basic operations, namely asserting, justifying and criticizing. In the course of explaining them, the term 'objection' was introduced as an expression of the operation of "criticizing" (see Wohlrapp 2014, Ch. 4.4). It refers to any move of an opponent claiming "that the thesis is not attainable through the present step or that this step is not feasible at all" (see Wohlrapp 2017, p. 165). Thus, an "objection" can take on a variety of guises (which can be classified, e.g., as criticisms, rebuttals, etc.; I will come back to it later). The background of this conception is a simple pragmatist thought pattern which directs my attention toward the practical basis of theoretical items. (Some closer explanation is given in section 3 of my answer to Derek Allen.) 
In his commentary Johnson has picked up several examples of my use of 'objection'. They are meant to demonstrate that the term is vague, heterogeneous, not well understandable. This demonstration, I am afraid, mainly suffers from misunderstandings. I will try to clarify the situation.

In particular, my commentator has considered three "objections" (Johnson 2017, p. 226), that I had enunciated, investigated, and refuted. These fulfill a conspicuous function within the theoretical development of the book. The paragraph in which they appear (Chap. 7.3) is concerned with providing an explicit justification of my own criterion for "thetic validity". This justification is offered and (because this is a requirement of my dialogical conception of a justification) completed by considering several objections which I imagined to be somehow plausible; and which $I$ then show to be refutable.

As to the first example: The argument $\mathrm{O}_{1}$ "Objections are always possible" was not meant to be an example for my use of the term 'objection'; rather, I imagined it to function as an objection against the validity criterion. How this worked and what I thought to be a sufficient refutation of that objection, this is by all means explained in the subsequent text (pp. 280f). The argument goes like this: A theoretician to whom this criterion is proposed could dismiss it, based on of the opinion, that objections to a thesis are "always possible". If this were true, then obviously an "absence of (open) objections" would hardly ever appear-and the said criterion could not function as a real demarcation. But in the book I consider at length what this "possibility" could really mean and how, given those considerations, it fades away. I settle that objection (imagined by myself) for no other reason than to justify and save my criterion. The other two examples $\left(\mathrm{O}_{2}, \mathrm{O}_{3}\right)$, cited in Johnson's commentary, are of similar structure and meaning. The three objections certainly have different contents and the ways of settling them are fairly different too, but they are all equal with regard to their function as "objections". 
Despite these apparent misunderstandings I have to admit that Johnson is right in pointing out a double meaning in the use of the term 'objection' in TCA. For one, it designates an instance of the operation of criticizing; however, it can also refer to the accomplishment of that operation ${ }^{21}$, in which case it would be called 'refutation'. Furthermore, he is right in observing that in my approach 'objection' is a generic term covering any type of oppositional content. I have explained above why I invented a term with this broad meaning, but this view is insufficient for Johnson. He thinks it necessary to draw sharp distinctions between objection, rebuttal, criticism, counterargument, refutation, alternative position etc.

I have no problems with making further distinctions, if (a) they can be described as having clearly different functions in the argumentative process and if (b) we can characterize them such that their use for specific concerns is obvious, without, however, forcing unnecessary constraints on the future argumentative process.

With regard to these issues, the following general reservation applies: If we elaborate our theory into precise distinctions, descriptions, and mandatory standards for all kinds of argumentative situations we risk restraining the arguers in their freedom of following the ways they deem appropriate for the needs of any given concrete case. Therefore, I consider a tendency to map all possible details of argumentation as counterproductive. Argument, with regard to its intrinsic constitution, must keep a general openness. $^{22}$

\footnotetext{
${ }^{21}$ Derek Allen has found out, that the same double meaning applies to the term ,justification', see Allen's comment and my answer in the proceedings of the 11. OSSA conference, May 2016.

22 See my pleading for "minimalism in argumentation theory", Wohlrapp 2014, pp. $121 \mathrm{ff}$.
}

(C) Harald R.Wohlrapp. Informal Logic, Vol. 37, No. 4 (2017), pp. 247-321. 


\section{IV - 3. "Dialectical tier", "Dialogical character" and the "Non-interactive audience"}

In my view argumentation is dialogical. The reason for this is its reflective character: Arguing is an activity which is supposed to be right, correct, well done, etc., and which therefore needs not only be performed but also, at the same time, critically observed. Is this enough to justify a general "dialogical" character? This depends on the meaning of 'dialogue', which is a word of colloquial language with a broad variety of uses. Even in argumentation theory it is used in fairly different ways. Despite this variety, there have been some criticisms of a principally "dialogical" character of argument, which, however, I consider not being pertinent. ${ }^{23}$

Despite his invention of the "dialectical tier", Johnson holds that my dialogue model falls short of being suited for a general theory of argument. He refers to an argumentative setting of an arguer in front of an audience that is just listening and not responding to the arguments. This setting has been dubbed the "Non-Interactive-Audience" (Govier 1999, Ch. 11) (hereafter NIA). In the NIA there will be no opponent; and even if the proponent knows about a certain objection and tries to settle it, Johnson muses that "there is no interlocutor to agree that the response to the objection is satisfactory" (Johnson 2017, p. 225).

This consideration shows that his "dialectical tier" is, on the one hand, more open - because it does not require a general dialogical setting. On the other hand, it is also more demanding, because the critic (viz., opponent) is supposed to receive a "satisfactory" response to his/her objections (or criticisms). This demand outlines a considerable difference between Johnson's view and my own regarding what a "satisfactory" answer to an objection is supposed to be.

${ }^{23}$ In TCA, Chap. 2.7, I have dealt with several different meanings of 'dialogue', their merits and shortcomings.

(C) Harald R.Wohlrapp. Informal Logic, Vol. 37, No. 4 (2017), pp. 247-321. 
For my commentator, it has to be determined by the opponent's endorsing the received answer. The fulfilment of this demand is called a "dialectical obligation". Good argumentative practice, he holds, takes place only if the participants discharge their dialectical obligations.

This view is a consequence of the basic decision about the general aim of arguing; for the "Informal Logic" school, this is "rational persuasion". Persuasion takes place only if an audience really accepts the message that a speaker wants to communicate. Therefore, if that "audience" advances critical contributions they have to be addressed by the speaker in a satisfactory way.

This shows that the NIA poses a real problem to an Informal Logic theoretician who demands a "dialectical tier" as a constituent of argumentative practice. In the NIA there are no objections and, even if the speaker settles an objection that is known to $\mathrm{him} / \mathrm{her}$, there is no answer by the audience regarding whether or not the settlement is accepted. Therefore, with regard to the NIA, the (persuasive) quality of the arguments remains dubious. To state it clearly: The NIA poses a serious problem for the implementation of a "dialectical tier" into the tradition of Informal Logic.

Johnson seems to believe that my general dialogical setting also struggles with that NIA and he apparently asks me, how that problem is handled in my theory.

The answer is, that for me, an opponent is taken to be satisfied by an answer to the advanced objection as long as $\mathrm{s} / \mathrm{he}$ does not utter any further objections to that answer. This kind of "satisfaction" does not even include the request to actively and consciously agree with that answer. The acceptance by an interlocutor is secondary if the aim of arguing is not the (rational) persuasion of an audience but the achievement of a valid new orientation with respect to an orientation gap. 
The reasons for my thesis may be as good as possible-still, nobody should be urged to accept what I am purporting (education is a specific case here). Insight is an inner process. As I have already explained in my answer to Katharina Stevens, it cannot be enacted by another person. Furthermore, a failure to accept can have many different causes: an absence of interest in the matter, slow-wittedness, a rejection of my worthy personality, bad mood, lack of humor, etc.

In my theory a failure of acceptance becomes relevant only when it is justified with an objection against my thesis or arguments. This is the reason why I would simply not regard a NIA as an interlocutor in an argumentative setting. It is an addressee for the promulgation and dissemination of my thesis, but not for its critical supervision.

I can imagine that Johnson is not satisfied by my solution of his "satisfactory" problem.

Again, the reason is, that rational persuasion is taken as the task of arguing. Sure, this constraint requires that an answer to an (actually delivered or only imagined) objection is approved by the interlocutor. Therefore, it is blatantly obvious that the NIA causes a problem for the Informal Logic approach, as soon as the "dialectical tier" is accepted. It seems as though Johnson invites me to care for a problem as endangering my approach, which indeed causes some trouble for his own.

I would really like to provide him with a good idea, but that would very likely mean modifying the task of persuasion as constitutive for argumentation. Therefore, the best advice maybe to try the line of thought which is presented in TCA. There, the persuasive side of argumentation (which certainly matters) does not appear in an external and empirically verifiable effect, but only as the attempt at providing "insight", i.e., a mental overcoming of an orientation gap, viz., an adjustment of a desired orientation.

(C) Harald R.Wohlrapp. Informal Logic, Vol. 37, No. 4 (2017), pp. 247-321. 


\section{IV - 4. Determination of thetical validity in front of "The open forum of arguments"}

Now I turn to a problem which I consider to be the most important regarding the criterion of thetical validity. As Johnson notes rightly, there are several possibilities to deal with objections. Concerning the arrangement in TCA, he has discovered the following problem: It is clear, that the opponent's moves can contribute substantially to the validity of the thesis under discussion. There are basically two possibilities: the opponent may agree or disagree (and thus object) with the steps of the justification that is advanced by the proponent. In reality, however, these possibilities may not appear in their pure or ideal form. Two kinds of risks should be considered: For one, an opponent's agreement may be so poorly reasoned "that a colleague standing close may say: "Not so quickly"' (Johnson 2017, p. 226); and, secondly, an opponent could also be "too slow": grumbling, demurring, behaving "plain stubborn" (loc. cit., p. 228), or seemingly unwilling to accept the proponent's moves.

I fully concede that Johnson is right in presenting this problem. Its solution requires a clarification of the relationship between the "dialogue model" and the real speech situation in which argumentative activities take place. I think we all agree that a criterion which applies only on the abstract level of the theoretical model, cannot lead to a reasoned judgement about the validity of a thesis. We have, however, developed an idea to bridge the gap between the abstract theory and the speech reality. It is called "The open forum of arguments". I will briefly explain the line of thought in four steps.

(1) If I raise a thesis, I believe that it is correct; but I do not know this. If I reflect on this ignorance, my reflection amounts to an acceptance that the thesis can be wrong, false, one-sided, etc. This acceptance is then modelled in the role of an opponent who critically supervises the justification for the thesis. That a defect can show up, this is operationalized in the opponent's 
advancement of an objection. Thus, on the meta-level of reflection, holding a thesis, is always accompanied by the willingness to settle all the objections that might be advanced in a dialogue.

(2) This dialogue, however, is not a real event. It is an abstract entity, a model with by which we (as partners in an argumentative exchange, or as solitary reasoners) can describe what happens and we can understand it with regard to the aspiration for some new and reliable orientation. Even if the real communication partners may usually be caught in their filter bubbles and behave in their own idiosyncratic ways, for us (as participants, or observers, having this model in mind) their utterances solely count in their dialogical function of justifying or criticizing (a part of) the argument. How can this be ensured? Is there some super-observer with a god's eye who helps to safely penetrate the real communicative jumble?

(3) This is where the construction of the "Open Forum of Arguments" comes in. In real argumentative activity, a series of arguments may have been advanced. Taken together, they form a certain "state of arguments" which enables an evaluator to judge the validity of the thesis. This state of arguments should not, however, be taken as the final and definite display of all the arguments that are available regarding the thesis. Real arguers always have limitations: of knowledge, of understanding, of fantasy, of communicative competence. With regard to these, the respective state of arguments and, thus, the resulting judgment of validity, have to be seen as "open". Any new argument, that appears can change the picture. An actual statement of the thesis as valid, expresses the confidence, that it can be maintained even when further arguments arise.

In TCA, this arrangement is described at some length under the name "The open forum of arguments". Every actual state of arguments has to be understood as an instance or an episode of that open forum. Therefore, if an opponent accepts "too quickly", this means, that the colleague who stands close, has an argument in mind, which needs to be inserted into the dialogue 
where it may change the state of affairs. A similar provision is provided for those opponent moves that fail to serve as a means of scrutinizing the thesis (cantankerous stubbornness, etc.). As it were, they are not taken to be definite but may always be completed or improved by additional arguments.

(4) The last step takes us back to reality. For one, a judgment about the validity of a thesis (in this sense) can never claim to have some final or even absolute suitability. However, it has to be considered "provisionally final", because we have to come to grips with our orientation gaps - and this has to take place within the limits of the available degrees of competence, and also, of course, by the given amounts of time. Therefore, the ascription of validity is theoretically open, but practically it is conclusive, because the respective thesis enters our subsequent life practice, where it becomes part of our more or less conscious shaping reality. To be sure, its ongoing theoretical openness must still be accepted, until (and iff) it looses its thetical character and becomes knowledge. But even until that (possible) change in its pragmatic stance takes place, it retains an enigmatic character. A reasonable human being should certainly be open for a revision and improvement of his/ her guiding orientations. But, on the other hand we tend to stick even faster to those beliefs that we have won as results of our argumentative reasoning - in particular if, in attending to them, some corresponding practical experiences have shown up.

I would like to add two more remarks considering the relationship between "thetical validity" and the "open forum of arguments". They may further clarify the different characters of Johnson's and my theory, in mutual illumination.

(5) The concept of validity has to go beyond the horizons of actual dialogue partners. If it were restricted to their proper perspectives, then the predicate "valid" would amount to a relativistic view of argumentative results. Relativism is a weak pseudo-solution to the general question of the epistemological virtue 
of argument. Thus, the conception of thetical validity is an attempt to provide a universalization which is not as definite as the one in knowledge (knowledge is never knowledge for someone) but on the other hand avoids the shallowness of relativism. Johnson (here agreeing with most of the followers of an epistemological approach) believes that a result of a good argument be "true". Yet, he is obviously not sure about a definite characterization of that argumentative "truth", because he considers it to come in degrees (a proposition may be "truer" than a second one $)^{24}$. I can only briefly state in this context that the completion of thetical validity with the "open forum of arguments" includes a kind of "midrange universality" (see Wohlrapp 2014, Ch. 7.1). This I consider to be an appropriate answer to the expectation that argumentative results are (at best) valid not only for you and me, but can claim to have a certain universal range.

(6) One last remark about Johnson's way of dealing with objections might be useful. The assumption of a "dialectical obligation" has led him to the question of how to specify the objections, criticisms, rebuttals, alternative positions, etc., that an arguer can be obliged to care for. ${ }^{25}$ This question was called "the Specification Problem" (Johnson 2000, pp. 327ff.). A tentative answer was that the arguer should concentrate on the "significant objections". But it was soon obvious that this is only a word. After many ruminations, Johnson has left it as a task for further research "to develop the idea of what it is for an objection to be significant" (Johnson 2000, 333). Here is my proposal: What can be advanced as an objection to a thesis depends on the thesis and is, in that sense, of an indefinite variety. Thus, there is no non-arbitrary answer to that question possible. This seems to be a sufficient reason to give up on Johnson's design of

${ }^{24}$ See Johnson 2000, pp. 65, 198, where he considers, and even demands, "degrees of truth".

${ }^{25}$ Govier, who has (reluctantly) taken up the idea of an indispensable "dialectical tier" in argument, has, ruminating over that question, come to the result that the amount of possible objections is indefinite. See Govier 1999, Chs. $12,13$.

(C) Harald R.Wohlrapp. Informal Logic, Vol. 37, No. 4 (2017), pp. 247-321. 
a dialectical tier. If that tier's conception is changed in the way I have described the reflective dialogue setting, then a specification of significant objections is always achieved concretely for any specific case and the general question is answered in the development of the "open forum of arguments".

\section{IV - 5. Undiscussed arguments}

Finally, Johnson comes up with an interesting and somehow whimsical consideration. If there is no discussion about a thesis then, trivially, that thesis will stay free from (open) objections. Does it not have to be deemed valid in Wohlrapp's system? Thus, any author who is not received at all could comfort him/herself with the consolation that at least a certain kind of validity (invented by some obscure German professor of philosophy) can be attributed to his/her views.

If this sounds plausible then, I am afraid, because of a profound difference in the underlying conception of evaluative predicates (like 'valid', 'correct', 'true' etc.). Johnson seems to understand them as designating qualities, that can be ascribed "objectively", i.e., from an external position, on the basis of criteria which can be checked without any subjective participation (maybe even by a machine). In my view, this is a variant of "metaphysical realism", a position which blows up common sense as a prestigious philosophical standpoint. What is obviously missing, that is the subject of the evaluation.

The lack of awareness of the subjective side is, what I consider the main shortcoming of Johnson's otherwise well reflected and diverse argumentation theory. My insistance on the importance of the "subjective side" does not only refer to the involvement of the participants in argumentation. It is a more fundamental issue: All the qualities of arguments, and of the results of argumentative efforts are not just "there", but they stem from ascriptions made by the participants. If the members of some obscure sect believe that they have good arguments for the ex- 
istence of a benevolent demon, protecting them exclusively, then the goodness or badness of those arguments is not a question of an objective quality (yes, they are probably bad, I hasten to confirm), but rather of critical arguments that "we" have and that lead to the result that their belief is illusionary.

Back to Johnson's assumed validity of a non-received thesis: In German there is a proverb which would literally be translated as: "What I don't know, won't make me hot.",26. The crucial question is: Who shall ascribe validity to the thesis of a book that nobody is interested in? Maybe the author has delivered a justification, and then, if no one else, at least he himself has endorsed it as valid. This would be the state of argument around his thesis; he would use it and be more or less happy. What is wrong with such a result? Now, if someone prefers to describe the state of the affairs like this: The author only believes that his thesis is valid, then this would require some knowledge of objections, which, again, would require that an evaluator has checked the justification and has found it defective.

In the terms I provide in TCA, a procedure of this kind would be described in the following way. The said evaluator has introduced at least one new argument into the former "state of arguments", so that the result has now been changed. Yet, there was no fault in calling it "valid" on the basis of the former state: This qualification does not include a demand for anyone else to believe those things 27 .

Is this so strange a view? Is it not rather the case, that, for many or even most of the orientations which we employ to master our lives, we have never asked for a justification. We routinely apply what we have learned and furthermore trust our

${ }^{26}$ There is a parallel in English also, but with a slightly different metaphorical content.

${ }^{27}$ A demand to believe is never included in any theory - not even in those theoretical systems that are qualified as „knowledge“- at least not in a liberal society. In education knowledge is taught because we are convinced that the functioning of society depends on a common level of (basic) knowledge.

(C) Harald R.Wohlrapp. Informal Logic, Vol. 37, No. 4 (2017), pp. 247-321. 


\section{Harald Wohlrapp}

good intuitions? ${ }^{28}$ Johnson thinks that, since mere agreement is not enough for validity (this was the objection, I tackled above), the mere absence of objections is not enough either. This is just trivially true for all (possible) orientations that move outside the realm of argumentation: they have not been fed into the critical machinery of the argumentative dialogue. Therefore, there is simply no sense in ascribing validity to them. Yet, as soon, as they are claimed to be "valid", they (may or should) enter the argumentative dialogue.

\section{Part V}

\section{Reply to David Hitchcock: "Transsubjectivity"}

Hitchcock's commentary is a fine representation of the last chapter of my book, which is titled "Transsubjectivity". This topic is certainly the most uncommon of all my proposals concerning a modern conception of argument. At the same time, it is the peak of the whole idea and needs to be carefully explained. I can really count myself lucky to have David Hitchcock having produced this short and stringent elucidation of my thought-line that is arguably unsurpassable.

Despite his excellent work, I am not sure that the idea is understandable without a profound study of my book. Therefore, I will extend his commentary by developing three aspects of the theory a bit more. These are: (1) the general theoretical design, (2) the role of subjectivity in argument and (3) the nature of the Principle of Transsubjectivity. After this I will suggest (4) some

\footnotetext{
${ }^{28}$ Here the famous "epistemic responsibility" of which, e.g., Bonjour is convinced (see Bonjour 1985, p. 8), seems to apply; viz., to reveal its illusionary character.
}

(C) Harald R.Wohlrapp. Informal Logic, Vol. 37, No. 4 (2017), pp. 247-321. 
comments about the comparison with religion and try to answer the three reservations that Hitchcock has indicated.

\section{V - 1. The general theoretical design}

"The Concept of Argument" is not meant as a full-blown theory of argument - but as a philosophically grounded sketch, offering key concepts, distinctions and basic ideas.

The first and most basic idea is the localization of argument in human life. There is a consensus that arguing is an integral part of men's cognitive activity. What is its specific concern? My answer is: Our need for orientation, for its maintenance and development.

Human beings are, as long as they live, in activity. Even if they are "doing nothing", or when they are contemplating, they pursue their life. And as their life is - to a certain extent-selfdetermined, they are in need of orientation. The question is always: How to go on? Basic orientation is granted in social upbringing (viz., by evolution). It is an amalgam of knowledge and practically confirmed beliefs, tied together by emotions (feelings of right and wrong). On basic orientations we can stay in normal situations for a while. But then we are confronted with its limits. This is when knowledge and habitual cognitive activity don't suffice any longer. This situation, which I call an "orientation gap", is the systematic vantage point for argument.

At this point all the orientation which was successfully working until now, is "old theory". I speak of "epistemic theory". In order to bridge a serious orientation gap, new theory has to be generated. This is called "thetic theory". Its first step is the raising of a thesis. This shows the pragmatic function of what we do when we put forward a thesis: We attempt to close an orientation gap. Obviously the mere claiming is not enough. A thesis has to be substantiated with a justification. Such a justification connects the thesis with epistemic theory, i.e., with theory that is already proven in its orientation function. (For this task all kinds 


\section{Harald Wohlrapp}

of known inference forms and argument schemes are used.) Thesis and justification, however, are brought about by a specific person and can insofar be biased or mistaken. In order to critically control the steps of the justification we need a second person (or a second level of reflection in the sole reasoner) and, thus, arrive at a dialogical setting of proponent and opponent. Sometimes a thesis can be justified in such a way that the opponent cannot raise any further objection endangering the justification. In such a case the thesis stays "free from open objections". In my view this is the target quality for a justified thesis, in TCA its name is "validity". As thetical validity is not knowledge or truth, this quality is in itself not universal. At at the same time it is not simply limited to those who accept it but includes a tendency towards universality. Therefore, the concrete dialogue has to be taken as an instance of a "forum of arguments" - which opens up every time a new argument (a new step in the justification or a new objection) appears.

This short overview of the theoretical design should enable a reader to now understand that the main function which an argument has to bring about, is trust: trust that the thesis - which is essentially no more than a product of our creative intellect - can be trusted if it is applied as a "new orientation".

\section{$\mathrm{V}-2$. The role of subjectivity in argument}

In Hitchcock's explanations subjectivity is mainly defined through being committed to one's own orientations. I hope it fosters understanding if the nature of these commitments is a bit more elucidated. In TCA there is one whole chapter (Chap. 3) dedicated to the topic of subjectivity. I found it important because of what might be called the subjective "conditions of possibilities" (in Kant's terms) of insight. In the extant argumentation theories these are ignored, which has to be considered a great lack. Why? Because, whatever criteria for good or correct arguing we might establish, it will ultimately be a subject, a person or a group, who accepts or refuses an argument, viz., a con- 
Replies to commenators on The Concept or Argument 313

clusion. In general, we accept what bestows on us an insight; and we refuse what we don't understand or what we mistrust. So it transpires that some people find the same argument extremely plausible and convincing, whereas others shake their heads about such downright nonsense. I think it is evident that we need some theoretical fabric in argumentation theory to describe and understand how this is possible.

This is what made my research group ask for some distinctions and constructions to theorize these indeed astounding, but common, aspects of argumentative practice. To simply assume that those phenomena merely expose different beliefs is insufficient, because it fails to apprehend the connectivity and persistence of those beliefs. And it is these qualities that can best be grasped in a pragmatist view.

Let us look at it in this way: In the course of our lives we acquire and build a great number of beliefs that are not just arbitrary opinions but that are acquired and kept because of their orientation value. Those beliefs stem from learning as well as from personal experience or research. They are not a chaotic collection but belong together and form a system, shaped by the person's habitual ways of perceiving, thinking, acting, preferring. In Hamburg we have called this an "orientation system" (OSY). It is an intricate assembly of parts of knowledge, personal experiences, accepted information, believed rumors, fantasies, fears, etc., being connected, glued and clotted with emotions. The OSY is decisive for people's dealing with arguments. Roughly speaking one accepts what fits with the orientation system and dismisses what is alien to it. Crucial borders are usually demarcated by frame structures. The predominant quality of the system is the mutual confirmation of its parts which leads - the longer it orientates the subject's life and activities - to a considerable stability and reluctance to change.

In the usual course of events the acceptance or dismissal of arguments is rarely a conscious decision, rather it is a kind of immediate reaction, activating subconsciously the frame struc-

(C) Harald R.Wohlrapp. Informal Logic, Vol. 37, No. 4 (2017), pp. 247-321. 


\section{Harald Wohlrapp}

tures which are characteristic of the respective orientation system. Persuasion (in the traditional vein) makes use of those automatic reactions.

Another prominent aspect is that this system is "reflective". Among opinions, theories and emotions concerning all the relevant issues in the world, it contains a model of itself, a "selfunderstanding". It is this reflective structure that provides the chance for argumentation to be more than an exchange or a clash of (more or less) immediate reactions to claims or positions that are encountered. The reflective structure brings about the chance for change, i.e., for becoming freely convinced - and not only persuaded - by an argument.

\section{V - 3. The nature of the Principle of Transsubjectivity}

My readers should consider that this principle is not meant as a rule that could be conventionally established. Even less it is meant as a kind of super-norm, imposed by the pundits of argumentation theory. In my view it is a tendency which is integral to the process of felicitous argumentative activity. Hitchcock has correctly mentioned that I have designed it as a kind of framing of argumentation. This could be counter-intuitive if framing is mainly understood as a subconscious form of "seeing as". I think, however, that we should consider the possibility of its becoming manifest and thus the subject of a conscious decision.

The crucial issue is that our contemporaries, who see "enlightened egoism" as a cultural achievement, follow, as if it were natural, an implicit rule that could be called the "principle of subjectivity": As far as possible they act out their acquired orientations (including their wishes, preferences and feelings about what is right and wrong).

Following one or the other of the two principles is, in my view, not so much a result of a different choice, so that, e.g., the stockbroker would select subjectivity and the student of philos- 
ophy would select transsubjectivity. Rather, it is a different degree of self-awareness. The willingness to put up my orientation system for consideration with regard to its compatibility with yours stems from my awareness that I am not an island. Instead, we both participate in some basic cognitive and emotional unity that makes us human. Seen like this, transsubjectivity is an attitude emerging in the reflection on what I want and what I can expect in dealing with other persons, in particular in argument practice. Rather than being proclaimed by an external authority, it is my own clarified intention and interest to see my arguing governed by the Principle of Transsubjectivity (hereafter PT).

Above I mentioned that argument has to bring about trust about a justified conclusion being suitable for orientation in life. With regard to the PT, that trust reaches a new level. Not only do we rely on a concrete argumentation for our trust in a certain thesis, but we can realize that we generally ought to trust reason in argument as being the ultimate authority in the determination of our life and well-being. This is what I call "deep trust" in reason. Deep trust is not just an increase of trust, but a very peculiar form of it. For one thing, there is no trustee, for whose trustworthiness we had some evidence; for another, we have no real choice because we are committed by the circumstances of life. Therefore, deep trust in reason can be estimated as resembling religious faith in the secular age.

\section{V - 4. The comparison with religion}

Hitchcock has found an impressive wording for my intentions concerning this point. He writes that "in reasoning together we manifest a trust in the power of reason that is akin to the trust of the religious believer ... and we aim for a transcendence of our subjectivity that is a horizontal analogue of the vertical transcendence of religion" (Hitchcock 2017, p. 237). Despite (or, maybe, even because of) this fine grasp he doubts the legitimacy of my comparison of trust in reason with religious belief. He has depicted two main differences: In religion there is a promise of 


\section{Harald Wohlrapp}

personal salvation and there are rituals giving significance to prominent events of human life, like birth, marriage and death. Furthermore, he argues that the potential to overcome one's subjectivity can be realized (and possibly even to a greater extent) as care and unselfish love in the relationship to others. Thus, there are three objections on the table, which can certainly be deemed pertinent. I will try to settle them by providing some further clarifications.

First, I readily admit that the comparison of a belief in reasonable argument and religious belief is daring. Still, I will not discharge myself with the easy excuse that I have indeed spoken not of a religious, but only of a quasi-religious belief.

My defense will start with the repeated affirmation that I hold a pragmatist point of view as essential in the conceiving of these human circumstances. As soon as we consider a pragmatist understanding of the essence of religion the said comparison appears no longer so awesome or quixotic. Hitchcock has correctly summarized that in my view the substance of religion is the trust that mankind is in good hands, viz., that the world is ultimately good and right. This is again a case of "deep trust", it is even the greatest paradigm of it. After this, a religion can be defined as a form of cultivating deep trust. This definition, if perceived in a careless superficial way, looks like being stated from an outside, merely functional perspective (as, e.g., Emile Durckheim's (2012) definition of religion as the medium of social unity). Yet this is not so. The definition of religion as a cult form of deep trust is a completely reflective determination, given "from within". Maybe it helps to enact the following considerations. Faith involves trust. In the case of religious faith trust takes again that peculiar shape that I mentioned above. There is no neutral evidence available for the trustworthiness of the trustee. You have to trust in the beginning and then you can hope to achieve some certainty about the trustworthiness of the trustee. The true believer, however, is sure enough that he/she has no choice. $\mathrm{He} / \mathrm{she}$ is in a state of faith like a small child in relation to its 
Replies to commenators on The Concept or Argument 317

family (who does not necessarily provide just love and pleasure). At any rate, the family, viz., the parents or peers, represent for that child the highest authority in determining what there is and what ought to be done. If things run as normal, the child can reassure its well-being through behavior that accommodates to the expectations and wishes of the family. However, it does not always understand them and moreover it is not granted that they are even feasible for the child. Sure, the promise is usually there, but with regard to its fulfillment, trust is needed.

On the background of this view the following argument for the quasi-religious character of faith in reason seems to be at least plausible.

The practice of argument is the peak of human reason. Since the age of enlightenment human reason has taken over the throne of the superhuman power that granted the fate of man and world and was the subject of deep trust in religious ages. Now reason is the highest authority.

What does that mean? Human beings are today, due to technological means of different kinds, able to keep or destroy the human world. How these technologies are applied and how the life of future generations is affected by their present applications, all this is decided by the contemporary political, economic, juridical, scientific and cultural elites. Those decisions, however, are taken on the basis of arguments, and these arguments, in their very essence, outrun all the available knowledge of our leaders.

Consequently, we cannot know that they are right. At the same time everything is dead serious: we are not playing around. We have no choice but to stake our lives and the lives of our descendants on the reason incorporated in these decisions. Insofar as we here submit our deep trust, we have won a quasireligious faith in human reason.

What about people who claim to have no faith in human reason (I suppose, the majority)? As there is atheism and agnosti-

(C) Harald R.Wohlrapp. Informal Logic, Vol. 37, No. 4 (2017), pp. 247-321. 


\section{Harald Wohlrapp}

cism around religion, so there is misanthropy and misology (often disguised as a non-illusionary world-view) around people who unperturbably put their confidence in reason. Who has chosen the better part? The true believers have confidence in the unconditioned and unconceivable benevolence of God. The true reasoner may have confidence in the open and all-pervading potential of reason. In the end the humane potential is as transcendent as the divine. There is a difference, sure, but we are not able to conceive a clear and sharp distinction.

What about the two differences that Hitchcock has depicted - the promise of personal salvation and the rituals?

As to salvation, I would like to remind the reader that there is no traditional religion that includes a promise of personal salvation no matter how you are living. But even with a good and suppliant life, there is no direct trade-like relation between a rule-conforming behavior and a rewarding salvation. Therefore, it will be up to the believer to draw his/her strength, hope and confidence out of his/her real life performance. Was it even evident what a salvation of the person is? The true believer will not care for a salvation of any individual peculiarities and achievements (capabilities, titles, honors) but for the soul which is supposed to be a deeper level of the "person".

As to rituals, things seem to be as follows. In situations in which we explicitly and efficiently engage in argument, we often have conventions to protect reasonable arguing, or to dismiss at least the most striking obstructions and aberrations. We have rules about limiting the duration of a speech, letting each other speak out or playing down strong emotions. Here and there we can even find traces of real worship for reason. We have or had, e.g., very elaborated ceremonies around strictly regimented sermons and debates at some traditional universities (Oxford, Paris, Prague); and during the early triumphal period of the French Revolution they had the fêtes de la raison (festivals of reason). Still, if it is true that all those rituals are not so colorful and so- 
Replies to commenators on The Concept or Argument 319

phisticated as those of religious cults are, it is also true that the latter often degenerate to empty forms that are enacted without involvement and understanding. I agree that religious rituals can "give significance to peak events of human life like birth, maturation, marriage" (Hitchcock 2017, p. 238). Their binding power, however, which they certainly had in religious ages, has considerably diminished.

In my opinion the lack of reasoning rituals is on the one hand a symptom for an easy and uncomplicated social traffic; on the other it is indeed a sign of today's meagre estimation of argument, whitch itself is caused by the vast amount of tolerated misuses in politics and marketing.

Finally, I will briefly comment on Hitchcock's third argument. It is all right to proclaim that love and caring for others is a true realization of human potential, and also that they should be deemed more essential than any engagement in discussionhow ever reasonable it may be. This is almost self-evident; at any rate, on an abstract level. We should not forget, however, that in the concrete course of social life, there appear as well certain problematic versions of love and care, perversities and pathologies, like the helper syndrome, neurotic mother's love, mad love (amour fou), masochism, stalking, etc. I think those possibilities need only to be mentioned in order to achieve an agreement that also loving and caring may need a pinch of reason in order not to go astray.

\section{References:}

Allen, Derek. 2017. Wohlrapp's concept of justification. Informal Logic 37(3), 170-182.

Aristotle. 1950. Politics (ed. H. Rackham), London: Macmillan. Aristotle. 1960. Topica. In: Aristotle in 23 vols., Vol. II, Posterior Analytics and Topica, London: Heinemann.

(C) Harald R.Wohlrapp. Informal Logic, Vol. 37, No. 4 (2017), pp. 247-321. 
Bonjour, Laurence. 1985. The structure of empirical knowledge. Cambridge, MA. and London: Harvard University Press.

Durkheim, Emile. 1912. Les formes élémentaires de la vie religieuse. Paris: Félix Alcan. (Engl. Transl. The elementary forms of religious life, 1915).

Gettier, Edmund. 1963. Is justified true belief knowledge?, Analysis 23 (1963), 121-123.

Goldman, Alvin I. 1995. Argumentation and interpersonal justification. In Proceedings of the $3 r d$ conference of the ISSA, Frans H. van Eemeren et. al., (Eds.). Vol. 1, pp. 53-61. Amsterdam: SicSat.

Govier, Trudy. 1999. The philosophy of argument. Newport News, VA: Vale.

Govier, Trudy. 2017. Logicism and objectivity. Informal Logic 37(3), 211-222.

Hegel, Georg Wilhelm Friedrich. 1977. Phenomenology of the spirit (transl. W. Wallace). Oxford: Clarendon Press (German original 1807).

Hitchcock, David. 2015. Review of Harald R. Wohlrapp's The concept of argument, A philosophical foundation. Argumentation, DOI 10.1007/s10503-015-9365-3.

Hitchcock, David. 2017. Transsubjectivity. Informal Logic 37(3), 230-239.

Johnson, Ralph. 2000. Manifest rationality, A pragmatic theory of argument. Mahwah, NJ: Erlbaum.

Johnson, Ralph. 2017. Wohlrapp on the criterial side of validity: Some comments. Informal Logic 37(3), 223-229.

Sellars, Wilfried. 1968. Science, perception and reality. London: Routledge.

Stevens, Katharina. 2017. Does rhetoric have a place in Wohlrapp's theory of argumentation? Informal Logic 37(3), 183210.

Tindale, Christopher. 2015. The philosophy of argument and audience reception. Cambridge: CUP. 
Replies to commenators on The Concept or Argument 321

Wohlrapp, Harald. 2014, The concept of argument, A philosophical foundation. Dordrecht: Springer.

Wohlrapp, Harald. 2017. Précis of The concept of argument, A philosophical foundation. Informal Logic 37(3), 162-169.

(C) Harald R.Wohlrapp. Informal Logic, Vol. 37, No. 4 (2017), pp. 247-321. 